\title{
CONSTITUCIÓN ITALIANA Y ESTADO DE EMERGENCIA POR COVID-19*
}

\author{
GIUSEPPE MARAZZITA \\ Catedrático de Derecho constitucional \\ Universidad degli Studi di Teramo
}

TRC, n. ${ }^{\circ} 48,2021$, pp. 153-191

ISSN 1139-5583

\begin{abstract}
SUMARIO
I. Objetivo de la investigación y método de análisis II. El «modelo abstracto» de la emergencia jurídica. III. El «modelo positivo» de la emergencia. IV. Los actos normativos y administrativos adoptados para hacer frente a la epidemia provocada por el Covid-19 desde enero de $2020 \mathrm{~V}$. El «modelo concreto» de estado de excepción sanitario instaurado en los años 2020-2021 y su conformidad con el modelo constitucional.
\end{abstract}

\section{OBJETIVO DE LA INVESTIGACIÓN Y MÉTODO DE ANÁLISIS}

El Estado italiano, desde febrero de 2020, ha adoptado una serie de regulaciones de emergencia, que en gran parte siguen vigentes, para hacer frente al hecho extraordinario representado por la propagación de la epidemia provocada por el virus Covid-19. Estas regulaciones están recogidas tanto en actos legislativos primarios (decretos-leyes y leyes ordinarias), como en actos administrativos estatales (resoluciones del Consejo de Ministros, Decretos del Presidente del Consejo de Ministros, órdenes u ordenanzas ministeriales), así como en actos de los organismos territoriales autónomos (órdenes u ordenanzas regionales y municipales).

Más de un año después desde el inicio de la fase jurídica excepcional, es el momento de comprobar si y cómo se han aplicado y respetado los principios constitucionales en materia de emergencia en las distintas fases del estado de excepción. El objetivo de la investigación requiere proceder en tres fases.

* Traducción de Silvia Romboli (Universidad Ramon Llull, ESADE). 
En la primera fase es necesario, ante todo, delinear un modelo abstracto de la dinámica jurídica en tiempos de emergencia, para definir la función del Derecho extraordinario y su relación con el sistema normativo ordinario dentro del sistema jurídico general. Posteriormente será necesario reconstruir el modelo positivo de emergencia previsto en el texto de la Constitución y, por tanto, examinar la regulación constitucional de los distintos estados de excepción, la interpretación que de ellos ha dado la jurisprudencia, en particular la de la Corte constitucional, y también las regulaciones de nivel sub-constitucional que crean poderes extraordinarios adicionales capaces de hacer frente a las emergencias. En la segunda fase analizaremos la secuencia de actos extraordinarios adoptados para afrontar la emergencia concreta del Covid-19, para mostrar — más allá de las medidas singulares - el «modelo de respuesta» elegido, con especial atención a la asignación del poder de derogación entre Estado, Regiones y Municipios, pero, sobre todo, dentro del ente soberano, entre Gobierno y Parlamento (epígrafe 4). Al concluir este análisis intermedio, se podrá definir el modelo concreto de estado de excepción establecido en los años 2020-2021 para hacer frente a la pandemia viral de Covid19. En la tercera y última fase de la investigación seremos capaces de atar cabos de todo el razonamiento a través de la comparación entre el modelo positivo de estado de excepción (definido por la Constitución y la legislación de implementación) y el modelo concreto adoptado por el Gobierno y el Parlamento para hacer frente a la emergencia actual. El objetivo será responder a la pregunta que planteamos en la premisa, esto es, si y en qué medida se ha aplicado y respetado la Constitución de emergencia en las distintas fases del estado de excepción por Covid-19.

\section{EL «MODELO ABSTRACTO» DE LA EMERGENCIA JURÍDICA.}

\section{El hecho extraordinario}

Como se ha tenido la oportunidad de argumentar ${ }^{1}$, la emergencia jurídica es una situación «compleja», lógica y cronológicamente divisible en dos momentos: el evento que causa la emergencia y el estado de excepción, que se relacionan en términos causales en el sentido de que el primero es la causa del segundo. Sin embargo, su conexión no es directa sino mediada por el juicio de necesidad que representa el concepto relacional que vincula la situación extraordinaria al régimen de emergencia. Si bien el hecho que causa la emergencia y el estado de excepción son eventos (es decir, situaciones reales detectables respectivamente en el contexto social y en el sistema jurídico), la necesidad no corresponde a ninguna realidad sensiblemente detectable, sino, antes bien, constituye el nexo capaz de activar el

1 G. Marazzita, L'emergenza costituzionale, Giuffrè, Milano 2003, pp. 138 y ss. 
estado de excepción en presencia de una situación crítica. Por tanto, el modelo puede resumirse en la proposición: «ante una emergencia, se considera necesario un estado de excepción». La misma se compone de un supuesto (el hecho que causa la emergencia), de un juicio (sobre la necesidad) y de un estatus jurídico (de excepción).

Pasando a examinar los tres elementos que — en abstracto - configuran una situación jurídica de emergencia, es necesario partir de lo que hemos definido como el «evento que causa la emergencia» (también llamado «evento extraordinario» o «evento excepcional»). Este elemento abre la fase de carácter extraordinario, dando lugar y justificación a hechos posteriores y, en particular, a valoraciones sobre la necesidad de una intervención jurídica con contenido derogatorio y el establecimiento efectivo de un determinado estado de excepción capaz de afrontar y superar la emergencia.

Este primer elemento del modelo representa el presupuesto para las fases posteriores del proceso lógico y jurídico que culmina con la proclamación del estado de emergencia.

El mismo consiste en una situación fáctica peculiar que, en el momento en el que entra en contacto con un ordenamiento jurídico vigente, plantea un problema jurídicamente relevante que se puede resumir en la proposición: «el Derecho actual es inadecuado». Las características que nos permiten definir el hecho extraordinario y distinguirlo de situaciones similares, pero diferentes, son cuatro.

a) La novedad: el hecho extraordinario se produce en un tiempo o momento determinado. Los eventos que incluimos en esta categoría ocurren una tantum o raras veces y, cuando se repiten, lo hacen sin seguir una regularidad predecible. Cuando la recurrencia se vuelve regular y, por tanto, previsible en el an, en el quando y en el quomodo, el evento iría perdiendo su carácter extraordinario hasta que se pueda inscribir en los hechos comunes y se rija por el Derecho ordinario. Un evento es extraordinario porque ocurre inesperadamente, ocurre por primera vez o, al menos, de forma diferente a lo que ha sucedido en el pasado. Por esta característica, altera la convivencia civil, es una anomalía que despierta la alarma en la población e insta a las autoridades públicas a intervenir, fuera de los procedimientos y normas sobre la competencia comúnmente vigentes. Sólo ante la presencia de un hecho surgido de repente, novedoso, es legítimo abrir un paréntesis jurídico igualmente extraordinario. Fuera de estas condiciones, la intervención pública, al no poder invocar el contexto de emergencia como justificación, debe tener lugar en el cumplimiento de los procedimientos y competencias ordinarios.

b) El carácter provisional: el hecho extraordinario está destinado a revertirse en el tiempo. Esto quiere decir que, dado un día en el que esa situación comienza, se espera un día en el que dejará de manifestar sus efectos, aunque pocas veces sea posible conocer ex ante el momento exacto en que esto 
ocurrirá. Si, por el contrario, el hecho nuevo está destinado a persistir en el tiempo, no se puede invocar un contexto jurídico de emergencia. Dicho esto, hay que considerar que los conceptos de provisionalidad y estabilidad son «relativos»: de hecho, dado que ninguna situación es eterna, todo acontecimiento está destinado, tarde o temprano, a dejar de producir efectos. Cuando hablamos de provisionalidad frente a estabilidad, asumimos un umbral cuantitativo de permanencia en el tiempo, más allá del cual cierto hecho ya no es provisional, sino que tiende a perdurar. Esta peculiaridad del hecho de emergencia también lo distingue de otras situaciones similares. De no existir el requisito de la provisionalidad, no tendremos un evento que pueda enmarcarse en la emergencia, sino un simple cambio, o evolución, de la realidad actual, que el ordenamiento jurídico puede afrontar sólo en cumplimiento de las normas ordinarias sobre competencia y la producción del Derecho: sin, es decir, recurrir a un régimen excepcional.

c) La impredecibilidad: el hecho extraordinario no es considerado por el ordenamiento jurídico normalmente vigente, que se muestra, en diversos grados, no preparado para hacer frente al suceso. En una situación «normal», todos los casos concretos encuentran en el ordenamiento jurídico una regulación capaz de componer el conjunto de los intereses en juego. A la cuestión de derecho, que emana de la sociedad, el ordenamiento jurídico da una respuesta consecuente. En cambio, en una situación de emergencia, se verifica un evento no previsto por el sistema de reglas ordinarias que rompe el equilibrio entre el sistema jurídico y el contexto social: no todos los supuestos concretos encuentran en el ordenamiento jurídico una regulación predeterminada, el Derecho objetivo «se queda atrás» respecto de los hechos sociales así modificados, en el sentido de que resulta inadecuado para regular los nuevos acontecimientos. El efecto es que se altera la composición de los intereses normalmente garantizados: se encuentran vacíos normativos porque han ocurrido hechos inesperados que no se encuadran en ningún supuesto abstracto o, más frecuentemente, porque los hechos nuevos se vinculan, irrazonablemente, a otros hechos diferentes bajo un mismo género.

d) El carácter antijurídico: el hecho extraordinario lesiona y/o pone en peligro intereses jurídicamente garantizados. También esta cuarta característica, como la tercera, se refiere a los efectos que se determinan en el ordenamiento jurídico: mientras que la imprevisibilidad expresa la alteración del equilibrio entre casos concretos y abstractos, de modo que los primeros superan la capacidad calificativa de los segundos, el carácter antijuridico, por otro lado, evidencia el efecto de esta alteración que consiste en privar de la protección jurídica a los valores y posiciones subjetivas jurídicamente reconocidos. 
El hecho extraordinario elimina los presupuestos materiales para la implementación del Derecho, impide que una norma o un conjunto de normas continúen produciendo sus efectos. La construcción normativa permanece intacta, pero ve la tierra restarse bajo sus pies, ya no encuentra correspondencia en el mundo de las cosas. Las palabras normativas, pese a seguir siendo legalmente válidas y efectivas, de repente se convierten en letra muerta.

Si la naturaleza impredecible del hecho extraordinario rompe el equilibrio entre el sistema normativo y el contexto social, el carácter antijuridico rompe el equilibrio entre el ordenamiento jurídico y el sistema de intereses y valores del cual el mismo es una prueba y expresión. En el primer caso se producen efectos irracionales, ya que no están predeterminados; en el segundo, se producen efectos antijurídicos porque una serie de posiciones, aunque reconocidas, no son concretamente protegibles.

En resumen, por emergencia entendemos una situación fáctica sobrevenida, intrínsecamente provisional, que escapa a las previsiones del derecho ordinario, determinando efectos antijurídicos. Este constituye el primer elemento, esto es, el prerrequisito o presupuesto, del proceso lógico y jurídico que culmina con el establecimiento de un régimen de emergencia.

\section{El juicio de necesidad}

Pese a la etimología del término («lo que se revela»), la atribución del nomen jurídico de «emergencia» a un acontecimiento determinado no se puede dar por supuesta ni es automática, sino que consiste en un juicio de valor cuyo resultado, como en todos los juicios de este tipo, depende de las premisas que se hayan establecido.

Esto también porque, como se ha visto, un hecho es extraordinario sólo en relación con un determinado ordenamiento jurídico, mientras que puede no serlo en respecto de otro: si se produce una agresión militar o un ataque terrorista, que generalmente se consideran situaciones típicas de emergencia, pero esto sucede en un país donde tales hechos son trágicamente frecuentes, bien puede suceder que el Derecho normalmente vigente y las competencias ordinarias sean perfectamente capaces de abordarlo sin necesidad de excepciones o suspensiones.

Esta evaluación sobre el carácter de emergencia de un evento es precisamente el juicio de necesidad: la necesidad no es un hecho, sino el resultado de una evaluación «política» que tiene como objeto la ocurrencia de un evento con características de emergencia y la oportunidad de recurrir a instrumentos normativos excepcionales adecuados para hacer frente a ese evento. El juicio de necesidad relaciona el primer y tercer elemento del modelo, ya que encuentra en el evento de emergencia una demanda de calificación jurídica extraordinaria e identifica, en un determinado estado de excepción, la respuesta jurídica adecuada. 
Este juicio puede resumirse en la proposición: «es preciso intervenir con medios jurídicos extraordinarios». El mismo expresa la necesidad de garantizar la seguridad jurídica suspendiendo y derogando temporalmente el derecho objetivo: la solución de la continuidad normativa (entre el régimen vigente normalmente y el excepcional) es funcional para mantener la continuidad axiológica entre los intereses protegidos en tiempos normales y los protegidos en tiempos de emergencia.

Se ha dicho que el hecho que provoca la emergencia se relaciona en términos causales con el estado de excepción, pero la referencia a esa categoría requiere algunas consideraciones adicionales. En efecto, no se trata de «causalidad natural», por su naturaleza ineludible por estar fundada en leyes empíricas, sino, antes bien, de «causalidad jurídica», basada en leyes deontológicas y como tal resultado de una decisión humana.

La necesidad, que caracteriza la emergencia jurídica y que conecta el hecho de emergencia con el régimen excepcional, se diferencia de la necesidad concebida por las ciencias naturales porque el movimiento de la causa al efecto no es en modo alguno automático e inevitable, sino que implica una elección entre diferentes opciones y, por tanto, un sistema de valores capaz de orientar esta elección: es el momento de la elección el que hace de la necesidad jurídica una categoría completamente diferente de la que se utiliza habitualmente en las ciencias naturales.

Esta necesidad también significa que la producción normativa extraordinaria, a diferencia de la ordinaria, es una actividad jurídicamente obligatoria. La aprobación de una ley, salvo en los casos de las leyes constitucionalmente obligatorias, es una actividad dejada a la libre determinación del titular, quien puede atribuir relevancia y protección jurídica a valores e intereses que hasta entonces pertenecían al ámbito del jurídicamente irrelevante. Por el contrario, la producción legislativa extraordinaria presupone un conjunto de intereses y valores cuyo reconocimiento jurídico ya se ha producido y que no se cuestiona: lo relevante es la perturbación, por la emergencia, de las condiciones materiales para su concreta actuación. El estado de excepción representa la solución jurídica que debe adoptar el órgano competente para seguir garantizando, incluso en tiempos extraordinarios, la protección de situaciones dignas de tutela jurídica (función conservadora).

Se entiende, por lo tanto, que la urgencia es un concepto estrechamente relacionado con el de necesidad, ya que una necesidad que no es urgente no es concebible jurídicamente. La obligación jurídica impuesta a las autoridades públicas no solo es ineludible, sino que requiere la implementación inmediata de las medidas adecuadas para hacer frente al hecho extraordinario. De lo contrario, el ordenamiento jurídico aceptaría que ciertos intereses, a los que normalmente ofrece protección, se vean injustamente afectados, si no perjudicados.

El juicio sobre la necesidad del régimen excepcional consiste en una elección sobre el an y el quomodo del recurso a medios jurídicos extraordinarios e implica un margen significativo de discrecionalidad política. De hecho, dada la imprevisibilidad del evento que provoca la emergencia, la respuesta jurídica de ninguna 
manera está predeterminada por el sistema normativo y consiste en la síntesis de una multitud de evaluaciones, tanto de carácter fáctico como jurídico.

El órgano competente para valorar la necesidad, aunque realice una valoración que toma como parámetro el derecho objetivo, y en particular la ley fundamental, goza por tanto de una amplia discrecionalidad porque las normas que confieren competencias extraordinarias se limitan (y sólo pueden limitarse) a identificar el órgano de gobierno y los procedimientos a seguir, pero describen los casos de acuerdo con cláusulas generales, que se refieren puntualmente a conceptos jurídicos indeterminados: esta situación es la consecuencia inevitable de la imprevisibilidad del evento que causa la emergencia. Por lo tanto, el sujeto titular de poderes excepcionales, una vez respetadas las normas formales relativas al procedimiento, no pudiendo proceder a una simple subsunción del hecho en el supuesto abstracto, está dotado de una amplia posibilidad de elección.

De esta discrecionalidad deriva, para el titular del poder de excepción, una responsabilidad peculiar, tanto jurídica como política. En efecto, el respeto del principio democrático parece exigir que la última palabra, o en todo caso la decisiva, sobre la necesidad de un estado de excepción se deje al órgano directamente representativo. Dado que la necesidad no es un hecho sino sólo la síntesis de un juicio, el juicio de necesidad, a nivel cognitivo, se presenta como una opinión como cualquier otra posible. Este «pluralismo de necesidades» (es decir, la relatividad de los juicios sobre ellas) comporta que el titular del poder de excepción pueda ser sometido a la crítica política por las decisiones de emergencia que tome.

Además de esta consecuencia, se añade una segunda, en gran parte relacionada con la primera. Esta referencia a la necesidad, lejos de eximir al órgano titular del juicio del deber de explicar los motivos de sus decisiones, lo obliga, por el contrario, a justificar sus actuaciones, ofreciéndose a la crítica y valoración judicial.

\section{El estado de excepción}

Al haber analizado el evento extraordinario y el juicio de necesidad, llega el momento de analizar el estado de excepción, tercer elemento que completa lógica y cronológicamente el modelo de emergencia. Su función es adecuar el ordenamiento jurídico vigente, que se demuestra insuficiente, a las modificaciones de la situación fáctica, extendiendo la protección de los valores e intereses normalmente reconocidos por el sistema normativo a los tiempos de anormalidad: el estado de excepción tiene como objetivo evitar o contener los efectos antijurídicos del evento que provoca la emergencia, restaurando en la medida de lo posible las condiciones materiales para la aplicación del Derecho. La excepción es un «artificio» que asegura, incluso en situaciones de emergencia, la prevalencia de lo que es normal. 
El estado de excepción (también llamado «estado de emergencia», «régimen excepcional»o «regulación extraordinaria») surge de un acto jurídico de instauración, que es adoptado por el órgano investido de esta facultad por una disposición que confiere competencias extraordinarias. Esa disposición prevé los procedimientos a seguir para la activación del poder mientras que, en cuanto a las condiciones legitimadoras, generalmente recurre a expresiones genéricas o identifica las distintas situaciones en función de las medidas a adoptar: por tanto, corresponde al titular del poder de emergencia la tarea de «rellenar» la disposición legislativa de sentido y significados, en la consideración, o no, de que un determinado evento integra el supuesto excepcional y, por ende, permite activar los consiguientes poderes.

Si la identificación de los casos tiene una capacidad vinculante reducida, se debe realizar un discurso diferente para la parte en la que las disposiciones predispuestas para la emergencia identifican a los sujetos y sus poderes. En efecto, desde este punto de vista, la norma que proporciona competencias extraordinarias vincula fuertemente la actuación de los poderes públicos que, salvo que emprendan iniciativas ilegales con respecto al ordenamiento vigente, deben ceñirse estrictamente a lo establecido por dicha norma y en particular a: a) el órgano legitimado para declarar el estado de excepción (instauración); b) la naturaleza y los límites del poder del que dispone el órgano (a); c) el órgano legitimado, después del establecimiento del estado de excepción, para hacer frente al evento que causó la emergencia (poderes de emergencia); d) la naturaleza y los límites de los poderes del órgano (c).

Con respecto a la instauración del estado de excepción, podemos distinguir diferentes tipos en función de dos criterios: la forma de la instauración misma y la titularidad del poder de instauración.

En relación con el primer punto de vista, la instauración del estado de excepción puede tener su propia autonomía formal (instauración expresa) o puede tener lugar simultáneamente con la adopción de medidas concretas de emergencia (instauración implícita).

Bajo el segundo punto de vista, según que el titular de los poderes excepcionales sea, o no, el mismo órgano competente para verificar la existencia de los presupuestos legitimantes, podemos distinguir dos tipos de instauración del estado de excepción:

a) la autoactivación, en la que el juicio sobre la ocurrencia del presupuesto legitimante y la declaración (expresa o tácita) del estado de emergencia se atribuyen al mismo órgano que es titular de la competencia extraordinaria que será activada. Entonces podemos, en el contexto de la autoactivación, distinguir entre: a.1) el caso en el que este juicio sea posteriormente sometido al control de un organismo diferente que tenga la facultad de revocarla (autoactivación controlada); a,2) el caso en el que el juicio no está sujeto a ningún control (autoactivación libre); b) heteroactivación, en 
la que el juicio sobre la ocurrencia del presupuesto legitimante y la declaración (expresa) del estado de emergencia se atribuyen a un órgano distinto del titular de la competencia extraordinaria.

Pasando al contenido del estado de excepción, primero hay que decir que se trata de un subsistema de actos y normas que se injerta en la parte del ordenamiento jurídico que aún se encuentra vigente: este subsistema se caracteriza por: a) el carácter antinómico de sus preceptos:

b) la temporalidad de su eficacia; c) la funcionalización de los poderes en los que se manifiesta.

Las dos primeras características (el carácter antinómico y el provisional) están íntimamente conexas porque una regulación de emergencia solo puede identificarse por su presencia combinada: de lo contrario, tendríamos una norma ordinaria (provisional pero no antinómica) o una norma especial (antinómica, pero no provisional).

Empezando por el primer aspecto, se puede decir que el estado de excepción está constituido por una regulación antinómica con respecto a (parte de) aquella normalmente vigente, en el sentido de que se relaciona con ella en términos de suspensión y/o derogación, creando un ius singulare. La función de la regulación excepcional es restablecer el equilibrio del sistema, restableciendo los presupuestos materiales para la aplicación del Derecho objetivo y para la protección de los intereses y valores perjudicados o amenazados por el evento que causó la emergencia.

En particular, la suspensión indica el fenómeno por el cual las normas de emergencia privan temporalmente de eficacia a algunas normas ordinarias sin que, sin embargo, se dicte una regulación que las sustituya. El efecto innovador consiste en privar a determinados supuestos concretos de la regulación vigente hasta entonces, con la consecuencia de trasladar estos casos al ámbito de calificación de una regla general, respecto de la cual la regla suspendida es especial.

La derogación, en cambio, consiste en la capacidad de la regulación de emergencia de limitar el alcance calificativo de una norma ordinaria, respecto de la general, e introducir provisionalmente una nueva regulación de algunos de sus casos. A diferencia del caso de suspensión, la norma de emergencia no solo resta ciertos casos de la eficacia de una norma ordinaria, sino que ofrece la regulación de sustitución. En otras palabras, mientras que en la suspensión el caso concreto se traslada a la esfera de calificación de otra regla general (preexistente), en la derogación el caso concreto se incluye en la esfera de calificación de la misma regla de emergencia.

La segunda característica del estado de excepción es su carácter provisional: tanto la suspensión como la derogación, como fenómenos de emergencia, tienen un plazo inicial y final, más allá del cual retroceden permitiendo que el ordenamiento jurídico recupere su estructura original. Dado que el estado de excepción «sirve» para hacer frente a una situación extraordinaria, es decir, no prevista por 
el ordenamiento vigente, su objetivo último es «convertirse en una normativa que ya no será necesaria» y permitir el restablecimiento de la normalidad jurídica. Efectivamente, esta connotación cronológica del régimen excepcional queda reflejada en la simétrica naturaleza provisional del hecho que causó la emergencia.

La valorización de la naturaleza provisional del estado de excepción permite centrarse en la diferencia entre las normas de emergencia y las normas derogatorias de los tiempos normales (las denominadas reglas especiales) que, en el uso jurídico, comparten el nombre de excepcional.

El primer paso es bastante obvio: las normas especiales establecen una derogación permanente, mientras que las demás determinan una derogación provisional. El segundo paso parte de la consideración de la consideración diferente que el ordenamiento jurídico reserva al caso concreto que justifica la norma de emergencia, frente al caso concreto que da lugar a la norma de derogación ordinaria: el carácter provisional de la derogación implica la decisión política de no aceptar la permanencia de la existencia del supuesto que provoca la emergencia (epidemia, guerra, terrorismo, éxodo, etc.) sino de eliminarlo lo antes posible. En el caso contrario, esto es, cuando el ordenamiento jurídico predispone una derogación ordinaria (y por tanto permanente), significa que se ha decidido regular un supuesto cuya existencia se considera normal.

Si bien la regla de derogación ordinaria tiene como objetivo incorporar el supuesto específico y la regulación que la misma establece tiene, de hecho, el propósito de armonizarla con los otros casos (función conservadora), al contrario, la regla de derogación de emergencia tiene como objetivo «enfrentarse» a la situación y, por tanto, eliminar el supuesto que tiene como objeto (función evolutiva): la regulación que por ende se establece tiene como fin último el de superar la emergencia.

En cambio - en el plano axiológico- mientras que la norma especial puede representar el reconocimiento de nuevos valores e intereses (función también evolutiva), la norma de emergencia se limita a reafirmar la protección de intereses y valores ya reconocidos por el ordenamiento jurídico (función siempre conservadora).

Profundizando el análisis, por último, la regulación de emergencia garantiza la «certeza jurídica»: de hecho, la transición del derecho ordinario al derecho de emergencia, aunque, desde un punto de vista objetivo, «resquebraja la fijeza» del sistema normativo, obtiene el resultado de preservar la garantía de los intereses y de los valores amenazados por la emergencia. A la inestabilidad de las normas corresponde la estabilidad, y por tanto la certeza, de las posiciones sustanciales que estas reglas tienen la función de proteger («certeza de los derechos»).

Finalmente, la tercera característica del estado de excepción es el carácter funcional de los poderes de emergencia. Se ha dicho que la necesidad, que caracteriza la emergencia jurídica y que conecta el evento de emergencia con el régimen excepcional (según la proposición: ante el evento que provoca la emergencia, se 
considera necesario el estado de excepción), nada tiene que ver con la necesidad comúnmente entendida, porque el movimiento de la causa (hecho que causa la emergencia) al efecto (régimen de emergencia) no es en modo alguno automático e inevitable, sino que implica una elección entre diferentes opciones.

De esta manera, la necesidad representa también el criterio de modificación (provisional) del ordenamiento jurídico con ocasión de un hecho extraordinario: al evaluar qué medidas son «necesarias», se construye el estado de excepción, con lo cual hay que afrontar la emergencia.

Si entendemos correctamente la necesidad en términos de elección debida y fuente de responsabilidad, el estado de excepción estará compuesto por las derogaciones estrictamente necesarias para restablecer el equilibrio entre los intereses dignos de protección jurídica y las condiciones materiales para la aplicación del Derecho ordinario: hay que derogar (solo) lo necesario, es decir, no más allá de lo necesario para hacer frente a la emergencia. La necesidad así entendida es sinónimo de adecuación y representa un límite a las posibles derogaciones en tiempos de emergencia: referirse a ella dentro de un ordenamiento jurídico tiene una función que quiere limitar y no incrementar el poder.

La consecuencia es que el poder de emergencia es un poder que tiene como función, y que está por tanto condicionado a, afrontar y superar la emergencia: el fin último del poder de emergencia es «dejar de ser necesario». Los corolarios de esta conclusión son tres: a) la adecuación de cada medida de excepción al concreto contexto fáctico, esto es, el cumplimiento de la ratio de emergencia; b) el carácter «necesariamente» provisional del estado de excepción: si el supuesto de emergencia es por su naturaleza provisional, la respuesta jurídica resultante también debe ser cronológicamente limitada; c) la prohibición, para las medidas de emergencia, de afirmar intereses y valores distintos de los normalmente reconocidos por el Derecho vigente. El estado de excepción que caracteriza a la emergencia jurídica es la reafirmación, por medios extraordinarios, de intereses y valores ordinarios. En este sentido puede hablarse de la subsidiariedad del Derecho extraordinario con respecto al normalmente vigente.

Es importante comprender que el estado de excepción constituye solo una fracción del Derecho objetivo vigente en tiempo de emergencia. Incluso en ocasión de la máxima emergencia constitucional, la de la guerra, gran parte del ordenamiento jurídico vigente mantiene la capacidad de producir efectos: de lo contrario, si la Constitución en su totalidad fuera suspendida o derogada, seríamos testigos de una crisis constitucional o una hipótesis de emergencia «absoluta». En cambio, el único estado de excepción que puede ser objeto de análisis científico es el «relativo», que es interno a un ordenamiento jurídico, que en sus elementos fundamentales no se ve (no debe verse) afectado.

Sólo en esta situación es posible, en efecto, razonar sobre los límites del estado de excepción, es decir, cuál es el «mínimo constitucional» inderogable incluso en tiempos de emergencia. En este sentido, es necesario distinguir dos tipos de límites que encuentra el derecho excepcional. 
El primero surge del concepto jurídico de necesidad, entendido como criterio para modificar el ordenamiento jurídico en tiempos con carácter extraordinario. Estos son límites internos al estado de excepción, ya que se conectan con la relación de estricta adecuación e instrumentalidad que debe existir entre el régimen excepcional y el hecho extraordinario que lo justifica (funcionalización del régimen). No se permite suspender y/o derogar la ley vigente más allá de lo estrictamente necesario para atender el evento de emergencia.

Este primer tipo de límites se articula en una serie de prohibiciones que las normas y actos extraordinarios encuentran «necesariamente»: 1) no pueden tener eficacia permanente, sino que son intrínsecamente provisionales: si el presupuesto de emergencia es por su naturaleza provisional, la respuesta jurídica resultante también debe delimitarse cronológicamente (límite de tiempo); 2) no pueden tener eficacia más allá del territorio directamente involucrado en el evento de emergencia, o no más allá del alcance espacial identificado en la declaración del estado de emergencia (límite espacial); 3) no pueden tener eficacia en supuestos concretos distintos de los directamente afectados por el evento de emergencia (límite de objeto); 4) no puede hacer valer intereses y valores distintos de los normalmente reconocidos por el Derecho vigente: el estado de excepción que caracteriza la emergencia relativa es, de hecho, la reafirmación, por medios extraordinarios, de intereses y valores ordinarios (límite de contenido).

Además de los límites lógicamente deducibles del criterio de necesidad, hay una segunda tipología de límites, puramente normativos, que encuentra el estado de excepción. Se trata de los límites externos al estado de excepción, ya que no tienen fundamento en la relación entre los elementos constitutivos del modelo de emergencia (y, especialmente, entre la necesidad y el estado de excepción), sino en la relación entre el subsistema extraordinario y el ordenamiento jurídico en su conjunto: estos límites son la condición para afirmar la naturaleza jurídica de la regulación de emergencia, esto es, su conexión con el sistema actual.

Las medidas de emergencia no solo deben adecuarse a las circunstancias, sino que tampoco pueden derogar y/o suspender normas ordinarias que el sistema jurídico considera, expresa o implícitamente, inviolables. Se trata de límites al alcance antinómico del estado de excepción y, por ende, a la posibilidad de que este derogue/suspenda el derecho ordinario.

Los límites externos se articulan en dos subespecies: expresos e implícitos. Los límites expresos se basan en las disposiciones que confieren competencias extraordinarias, las cuales, como fuente de legitimidad de las medidas de emergencia, no pueden ser derogadas ni suspendidas por estas. Más concretamente, los límites expresos, es decir, directamente deducibles del Derecho objetivo, consisten en una serie de prohibiciones que se aplican a los poderes extraordinarios: I) no pueden ser ejercidos por sujetos distintos de los señalados en las normas de atribución del poder; II) no puede ejercitarse utilizando procedimientos distintos a los regidos por las normas de atribución; III) no pueden ejercitarse competencias (administrativas, jurisdiccionales o normativas) superiores, por naturaleza, 
eficacia y contenido, a las expresamente atribuidas. Finalmente, también existen límites implícitos porque la atribución de poderes excepcionales muchas veces no está predeterminada en todos sus aspectos por las normas que atribuyen esa competencia extraordinaria, y pueden haber amplios márgenes de indeterminación. Por tanto, es necesario buscar en otras disposiciones constitucionales, con un razonamiento lógico-sistemático, los límites que la norma que atribuye competencias extraordinarias demuestra presuponer. De esta manera, llegaremos a discernir, dentro de las disposiciones constitucionales, aquellos principios en los que se resume la identidad misma de un ordenamiento jurídico históricamente identificado. Derogarlos equivaldría a salirse de la (relativa) emergencia jurídica, porque ya no tendríamos el mismo ordenamiento jurídico en una configuración extraordinaria, sino otro ordenamiento en formación.

El corolario de la identificación de límites al estado de excepción es que la actividad de los órganos titulares de competencias de emergencia está sujeta a un control, no solo político, sino también judicial en términos de legitimidad. De hecho, cada uno de los límites identificados anteriormente (internos, externos explícitos y externos implícitos) representa una condición de legitimidad del derecho excepcional que debe ser verificada por jueces ordinarios y jueces especiales.

\section{EL «MODELO POSITIVO»DE LA EMERGENCIA}

\section{El poder de emanar decretos de emergencia previsto en el art. 77 de la Constitución}

Trazado brevemente el modelo abstracto de la emergencia jurídica, es necesario examinar el «modelo positivo», es decir, el conjunto de estados de excepción previstos por el ordenamiento jurídico italiano, con especial referencia a la hipótesis de la emergencia sanitaria y la consecuente crisis económica. A nivel constitucional, es necesario centrarse en el poder gubernamental de aprobación de decretos de urgencia previsto en el art. 77 de la Constitución y sobre el estado de emergencia económica previsto en el art. 81 Costo, mientras que, a nivel legislativo, vale la pena mencionar el poder de emanar ordenes u ordenanzas (potere di ordinanza).

Según el art. 77 de la Constitución «El Gobierno no puede, sin delegación de las Cámaras, dictar decretos con fuerza de ley ordinaria. Cuando, en casos extraordinarios de necesidad y urgencia, el Gobierno adopte, bajo su responsabilidad, medidas provisionales con fuerza de ley, deberá presentarlas el mismo día para su conversión a las Cámaras que, aunque disueltas, serán convocadas y se reunirán expresamente para este asunto dentro de cinco días. Los decretos pierden su eficacia desde el principio si no se convierten en ley dentro de los sesenta días de su publicación. Sin embargo, las Cámaras pueden regular por ley las relaciones jurídicas que surjan sobre la base de los decretos no convertidos». 
En el sistema constitucional, la posibilidad de emanar decretos de emergencia representa el poder general de emergencia, ya que constituye la función de hacer frente a situaciones extraordinarias que no pueden subsumirse en los supuestos especiales (artículos 78, 81.1 y 126 de la Constitución). Cualquier situación de crisis, que no sea una agresión bélica o una emergencia regional, está comprendida en el ámbito prescriptivo del artículo 77 de la Constitución. De esta manera, el decreto de emergencia se convierte en un centro de referencia para emergencias no identificadas expresamente: excluyendo las tres determinadas de manera explícita, generalmente le corresponde al decreto-ley restablecer los presupuestos materiales para la aplicación del Derecho y garantizar la protección de los valores e intereses jurídicamente reconocidos.

Es necesario aclarar que, al interpretar el artículo 77, adherimos a la lectura dominante ${ }^{2}$, según la cual el mismo contiene una norma que atribuye la competencia extraordinaria para ejercer temporalmente la función legislativa. Según la conocida tesis de Esposito ${ }^{3}$, posteriormente revisada ${ }^{4}$, el decreto-ley sería un hecho al que la Constitución busca dar una regulación, pero no un instituto que en ella encuentre fundamento. El Gobierno, por tanto, tendría la posibilidad, pero no la potestad de adoptarlo, mientras que al Parlamento correspondería el poder de convertir el decreto «viciado» o «no válido», que fue adoptado, eliminando así el presupuesto de la responsabilidad del Ejecutivo. El peculiar corolario de esta configuración es la cuestionabilidad de la ley de conversión debido a la ausencia de los presupuestos del decreto-ley (lo que contendría un vicio in procedendo).

De manera diferente, también en lo que respecta al espíritu racionalizador de la Constitución, parece que la existencia de una regulación expresa del decreto-ley atribuya una competencia (aunque sea de emergencia) para dictar actos perfectamente válidos, siempre que, obviamente, se respete el procedimiento ex art. 77 de la Constitución. Desde esta perspectiva, la prohibición al Gobierno de emanar, sin delegación de las Cámaras, decretos con valor de ley ordinaria, prevista por el primer párrafo del artículo, evidencia la naturaleza de emergencia, pero

2 Pueden verse V. Crisafulli, Lezioni di diritto costituzionale, Padova, 1984, p. 80 y ss.; Mortati, Istituzioni di diritto pubblico, Padova, I y II, 1975-1976, pp. 704 y ss.; PALADIN, Commento all'articolo 77, in Commentario alla Costituzione a cura di Branca, Bologna-Roma, 1979, pp. 52 y ss.

3 C. Esposito, Decreto-legge, en Enc. dir., XI, Milano, 1962 pp. 831 y ss.

4 La tesis de Esposito fue retomada, en varios escritos, por F. SorRentino, La Corte costituzionale tra decreto-legge e legge di conversione: spunti ricostruttivi, en Dir. Soc., 1974; F. SORREnTINo, Decreto-legge in fase di conversione e giudizio di costituzionalità, en Giur. Cost., 1991; F. Sorrentino y G. Caporali, Legge (Atti con forza di), en Dig. Pubbl., IX, 1994, pp. 15 y ss.; F. Sorrentino, Il decreto-legge non convertito, en Pol. Dir., 1995; F. Sorrentino, La reiterazione dei decreti di fronte alla Corte costituzionale, en Giur. Cost., 1996; F. Sorrentino, Fonti del diritto, Genova 1977 , pp. 72 y ss. Con respecto a las diferencias entre las dos reconstrucciones, cabe señalar que Sorrentino, a diferencia de Esposito, configura la ley de conversión como un verdadero bill of indemnity, asume que los actos emitidos sobre la base de decretos caducados, perdiendo retroactivamente la base jurídica, son «anulables» en las formas ordinarias y, en última instancia, considera que el decreto-ley no puede exceder del contenido disponible para la ley ordinaria, derogando la Constitución (ver última obra cit.). 
legítimo, del uso del decreto de urgencia. Pese a que la disposición del art. 77.1 parezca lógicamente encuadrarse dentro del art. 76, esta tiene la función de reafirmar la competencia «ordinaria» de las Cámaras, contraponiéndola también textualmente a la atribución de la competencia «extraordinaria» del ejecutivo.

Así como el primer párrafo del art. 77 de la Constitución especifica la competencia general establecida por el art. 70 del mismo cuerpo normativo, la referencia a la «responsabilidad» del Gobierno para la promulgación del decreto-ley es meramente repetitiva de lo establecido con carácter general por los artículos 94 y 95 de la Constitución. Es decir: el segundo párrafo del art. 77 de la Constitución no prevé una responsabilidad gubernamental autónoma, vinculada únicamente a la aprobación del decreto-ley. Responsabilidad cuya existencia no está mecánicamente conexa con la conversión del decreto en ley: de hecho, puede darse tanto el caso en que el Parlamento, si bien convierta el decreto, considere responsable al Ejecutivo de su promulgación, como, viceversa, el caso en que, si bien se deje caducar el decreto o incluso se rechace su conversión, no identifique los motivos de la responsabilidad del órgano controlado5.

La piedra angular adicional de la tesis imperante está representada por la «novación de la fuente» realizada por la ley del Parlamento, durante la conversión del decreto: la ley sustituye al acto gubernamental, restableciendo el orden de competencias de los tiempos normales. De esta forma, los defectos específicos del decreto (relativos a la existencia de las condiciones y al juicio de necesidad), una vez intervenida la ley de conversión, ya no pueden ser cuestionados.

El elemento clave adicional de la tesis mayoritaria es la «novación de la fuente» realizada por la ley del Parlamento, en ocasión de la conversión del decreto ${ }^{6}$ la ley sustituye al acto gubernamental, restableciendo el orden de competencias de los tiempos ordinarios. De esta forma, los eventuales defectos específicos del decreto (relativos a la existencia de los presupuestos y al juicio de necesidad), una vez intervenida la ley de conversión, ya no pueden ser cuestionados.

De la naturaleza general de la atribución de competencia legislativa de emergencia y, sobre todo, del tenor literal de la disposición deriva otra consecuencia. Leyendo el art. 77 de la Constitución pueden extrapolarse dos significados normativos, no alternativos sino concurrentes: un primer significado de percepción inmediata consiste en la regulación positiva del acto denominado decreto-ley, del procedimiento de emisión y del de conversión. Podemos definirlo como el aspecto positivo de la disposición, ya que establece lo que, en condiciones extraordinarias de necesidad y urgencia, pueden hacer el Gobierno y el Parlamento: las normas

5 Sobre el tema de la responsabilidad gubernamental puede verse, también para algunos ejemplos de división entre la suerte del decreto-ley y la del Gobierno, infra, párrafo 3.3.

6 Sobre el particular, v. PALAdin, Commento all'articolo 77, en Commentario della Costituzione, cit., p. 82, quien observa cómo la idea «de que las leyes de conversión son válidas para sustituir la fuente de las medidas provisionales del Gobierno se revela a su vez, sin embargo, llena de motivos de ambigüedad, aún presentes en el ámbito de los intérpretes». 
que lo componen se estructuran, en su mayor parte, de acuerdo con el modo deóntico del «permiso».

Se revela, no obstante, otro significado — por así decirlo— en la sombra y que, contrapuesto con el primero, podríamos definir el aspecto negativo de la disposición. Este significado está estructurado según el modo deóntica de la «prohibición» y se refiere a todos aquellos comportamientos de la autoridad — distintos del decreto gubernamental - que en abstracto serían capaces de hacer frente a situaciones de emergencia, pero que la disposición no permite. Afirmar, como dispone el art. 77 de la Constitución, que «en casos extraordinarios de necesidad y urgencia el Gobierno adopta (...) medidas provisionales con fuerza de ley», significa no sólo constituir una competencia gubernamental de emergencia, sino también excluir que los sujetos distintos del Gobierno, o el mismo Gobierno por medios distintos al decreto, puedan tratar esos casos recurriendo a la fuerza provisional de la ley ordinaria.

De esta manera, de esta disposición resulta existir una reserva de decreto-ley en casos extraordinarios de necesidad y urgencia que, aunque entrevista por la doctrina, no parece haber encontrado pleno reconocimiento. Es como si la disposición afirmara: «en casos extraordinarios de necesidad y urgencia sólo el Gobierno puede adoptar medidas provisionales con fuerza de ley». La constituyente reguló el caso en el que es necesario intervenir con una normativa de rango primario, pero no es posible recurrir a la legislación ordinaria o delegada: en este caso no solo se puede utilizar el decreto-ley, sino que se debe utilizar el decreto-ley (solo el decreto-ley).

Aceptada esta lectura del precepto constitucional, resultan ilegítimas todas las regulaciones que atribuyen, a sujetos distintos del Gobierno en su colegialidad, potestades normativas de urgencia, susceptibles de derogar la ley; de igual forma, parece inconstitucional que se reconozca al propio Gobierno el poder de derogar la ley para atender eventos de emergencia, fuera del procedimiento y de los controles establecidos por el art. 77 de la Constitución La ratio de la norma es precisamente la de excluir subversiones de la forma de gobierno parlamentaria atribuyendo al Gobierno una competencia reservada y sujeta a la convalidación de las asambleas representativas.

El presupuesto, en un sentido amplio, para el establecimiento legítimo del estado de excepción está constituido por los «casos extraordinarios de necesidad y urgencia». La expresión ${ }^{7}$, que también tiene su propia homogeneidad semántica, se puede diseccionar en dos sintagmas que, a su vez, no parecen ser más divisibles, representando los átomos de la partícula normativa contenida en el segundo apartado del art. 77: por un lado, encontramos los «casos extraordinarios», por el otro la «necesidad y urgencia». El primer fragmento del texto simboliza el ver-

7 En un enfoque positivista, en la reconstrucción del sentido normativo, no se puede ignorar la hermenéutica del texto, aunque, obviamente, esto no sea suficiente: especialmente en presencia de disposiciones constitucionales, es necesario ubicarse dentro del sistema normativo para comprender el alcance real de sus elementos singulares. 
dadero presupuesto fenoménico del decreto-ley, es decir, el «evento que provoca la emergencia» dotado de características peculiares; la segunda expresión evoca esa fase intermedia que, según el «modelo abstracto» descrito anteriormente, conecta el evento de emergencia con el estado de excepción y que denominamos «juicio de necesidad de decreto».

La naturaleza general del instrumento no permite un examen detallado de las condiciones que legitiman el uso del mismo: salvo en el caso de guerra y en los regidos por los arts. 81.1 y 126 de la Constitución, cualquier eventualidad extraordinaria autoriza el mecanismo de respuesta previsto en el artículo 77 . En base a lo elaborado, podemos decir, en general, que la condición imprescindible para la activación del poder de decretar está representada por la ocurrencia de un evento de emergencia.

Las situaciones de emergencia en las que, en abstracto, se cumple con las disposiciones constitucionales e, incluso, se precisa jurídicamente activar el remedio extraordinario previsto en el art. 77 de la Constitución se pueden ordenar en tres tipologías: a) supuestos de emergencia natural: incluye los diversos desastres naturales conocidos por la historia de los elementos (deslizamientos de tierra, inundaciones, desbordes, terremotos, erupciones volcánicas, incendios espontáneos) pero también la propagación de epidemias y pandemias no causadas por actividades humanas; b) supuestos de emergencia relacionados con la actividad bumana en el medio ambiente: es decir, desastres ambientales y diferentes tipos de contaminación (atmosférica, hídrica, del suelo, acústica) causada por sustancias nocivas (contaminación química, biológica o nuclear). Esta categoría también incluye epidemias dolosas causadas por la conducta humana voluntaria (por ejemplo, armas biológicas); c) supuestos de emergencias sociales: esto incluye el terrorismo interno, el terrorismo internacional, la emergencia mafiosa, la crisis económica.

La «necesidad y urgencia» es la segunda parte del fragmento normativo que establece las condiciones legitimadoras del estado de excepción regulado por el art. 77 de la Constitución. Para establecer el estado de excepción no basta con que ocurra un evento con características de emergencia, sino que es necesario que el órgano encargado de ello «reconozca» que existe la necesidad de derogar en vía extraordinaria el orden normal de competencias para hacer frente a ese evento con determinadas medidas. En el caso de los decretos de emergencia, la disposición, tras identificar el presupuesto básico en los «casos extraordinarios», requiere que el Gobierno asevere la necesidad de adoptar el decreto-ley. La expresión «necesidad y urgencia» expresa precisamente el segundo elemento del modelo de emergencia, esto es, la evaluación o valoración gubernamental, que sitúa el supuesto de hecho (no significativo y determinante en sí mismo ${ }^{8}$ ) en una relación de causa y efecto con la modificación jurídica extraordinaria.

8 En contraposición con la teoría antes mencionada de la necesidad como fuente jurídica, se debe negar una vez más que un evento pueda requerir un estado de emergencia, que una circunstancia «constituya una 
Es como si el art. 77 afirmara: "Cuando en casos extraordinarios el Gobierno considera necesario y urgente adoptar medidas provisionales con fuerza de ley, lo hace bajo su responsabilidad...»: la necesidad del decreto-ley nunca es un hecho ${ }^{9}$, sino que es la síntesis de una política de evaluación llevada a cabo por el órgano ejecutivo y luego controlada por el Parlamento. Este «juicio de necesidad» consiste en reconocer o no, en un determinado «caso extraordinario», una necesidad urgente de calificación jurídica e identificar en una determinada disposición provisional la respuesta normativa adecuada ${ }^{10}$. El sintagma «necesidad y urgencia» parece así expresar un concepto unitario ${ }^{11}$, «una endíadis» ${ }^{12}$, ya que no puede dividirse en otros (dos) conceptos que tengan autonomía, en la estructura del instrumento. Una necesidad no urgente no sería una verdadera necesidad y una urgencia innecesaria no justificaría el decreto de urgencia ${ }^{13}$.

manifestación explícita, imperiosa y categórica de necesidades y fuerzas sociales, en el sentido de que emana de forma inmediata y directa, sin incertidumbre y sin posibilidad de escapar de ella, una norma imperativa» (SANTI Romano, Sui decreti-legge e lo stato di assedio in occasione del terremoto di Messina e di Reggio-Calabria, ahora en Scritti minori, Milano 1990, p. 362). Un hecho — sea el que sea, incluso un hecho humano (un acto) — es, en sí mismo, incapaz de provocar una modificación en el ámbito jurídico, pero será el ordenamiento jurídico, calificándolo, que lo conectará con una consecuencia jurídica concreta: antes del juicio de necesidad, el hecho excepcional es «mudo e inerte». El hecho que sea obligatorio declarar el estado excepcional (la «regla imperativa» de Santi Romano) no surge del hecho, que es solo un requisito previo, sino de la decisión humana de recurrir a un instrumento de emergencia, según lo previsto constitucionalmente.

9 Contra v. Fresa, Le circostanze di necessità ed urgenza nella problematica del decreto legge, cit., pp. 71 y ss., quien habla de la urgente necesidad como un «hecho jurídico permisivo» o "presupuesto material del decreto-ley» (cursiva nuestra).

10 El nexo entre la insuficiencia del derecho ordinario para restablecer los presupuestos de protección jurídica y la necesidad de un estado de excepción, fue evidenciado de manera muy eficaz por quienes fundaron entonces la fuente última de todo derecho sobre la necesidad. «Lo que caracteriza a la necesidad que lleva al estado de sitio es la imposibilidad material y absoluta de aplicar las reglas que rigen la vida del Estado en determinadas condiciones y la necesidad no de aplicar las existentes, sino de emitir nuevas»; a continuación, el autor subraya como típico de la medida de emergencia precisamente «esta sustitución, aunque provisional y limitada en el tiempo, de un nuevo derecho objetivo al derecho objetivo existente» (SANTI Romano, Sui decreti legge e lo stato di assedio in occasione del terremoto di Messina e Reggio Calabria, en Scritti Minori, cit., p. 293).

11 Las fórmulas de los textos legislativos estatutarios expresaron, más felizmente, la singularidad del significado normativo: el art. 3 de la ley de 31 de enero de 1926, n. ${ }^{\circ} 100$, confiere al Gobierno la facultad de dictar normas con fuerza de ley «en casos extraordinarios, en los que razones de urgente y absoluta necesidad así lo requieran».

12 En este sentido, v. Fresa, Provvisorietà con forza di legge e gestione degli stati di crisi, cit., p. 51, según el cual «necesidad y urgencia» son una endíadis «al tener que hablarse de necesidad urgente o urgencia necesaria»; de hecho, «la necesidad de proveer es jurídicamente relevante sólo si la misma está tan cualificada con respecto al tiempo (es urgente), que no es posible referirse al orden normal de competencias normativas primarias».

13 Incluso la «urgencia innecesaria», si bien es posible, pertenece a hechos jurídicos, pero no a los de tipo de emergencia. Esta ocurre cuando: a) existe un plazo «esencial» dentro del cual adoptar un determinado acto y más allá del cual la adopción sería inutiliter data; b) la falta de adopción del acto no afecta a los intereses y valores jurídicamente relevantes. Como ejemplo, puede imaginarse que, en la creación de un organismo internacional, se establezca el plazo dentro del cual los Estados, que pretenden adherirse a él, deben adoptar las consecuentes decisiones internas. La expiración del plazo requiere sin duda una decisión rápida, pero no jurídicamente necesaria: la falta de participación, de hecho, no privaría de protección jurídica a ciertas posiciones, sino evitaría la creación de otras nuevas. La intervención jurídica simplemente urgente, entonces, tiene una función «evolutiva» de tipo ordinario, y no «conservadora» como ocurre en el estado de emergencia. 
Comprobada la necesidad de «un» decreto-ley, es necesario establecer el contenido del acto ${ }^{14}$ que, en concreto, debe emitirse. El criterio para la formación del estado de excepción es el de necesidad: para que el decreto urgente permanezca en el ámbito que le corresponde, el decreto-ley debe contener únicamente las disposiciones que son estrictamente instrumentales en relación con la necesidad de afrontar la crisis en curso.

El tercer elemento que completa la emergencia jurídica —el estado de excepción- está constituido por las «medidas provisionales» con «fuerza de ley». Estos actos se insertan en el ordenamiento jurídico general mediante la suspensión o derogación temporal del derecho ordinario: el decreto-ley da lugar a un estado de excepción, cuya capacidad innovadora ${ }^{15}$ se caracteriza por la misma intensidad y los mismos límites que la ley ordinaria. En cuanto a la extensión (subjetiva, objetiva y espacial) del régimen extraordinario, puede variar de un mínimo a un máximo que está condicionado únicamente por la necesidad de atender el caso extraordinario. Así, el poder de decreto puede afectar a grandes sectores del sistema normativo y de la comunidad organizada.

El mecanismo a través del cual se abre el paréntesis excepcional es el de la autoactivación controlada, para lo cual el Gobierno tiene tanto el poder de excepción, como la competencia para adoptar medidas de emergencia. Esta amplitud inicial de los poderes gubernamentales, necesaria para atender emergencias no predeterminadas, encuentra un contra-límite formal-procesal en la terminación automática ${ }^{16}$ del estado de excepción dentro de los sesenta días de su establecimiento (artículo 77 de la Constitución). La connotación provisional de poder excepcional está fijada directamente por la norma que atribuye esta competencia:

14 Contra L. Paladin, Commento all'articolo 77, cit., p. 56, estima que sólo la elección sobre el an se refiere a la necesidad «como elemento de calificación de los supuestos regulados»: «no hay que confundirlo (...) con la conveniencia política del acto, aunque corresponda al Gobierno la elección de cómo tratar cada caso (la elección del quomodo). V. también Lavagna, Istituzioni, cit., p. 320.

15 El carácter provisional que caracteriza a las normas de emergencia (es decir, normas que consisten en una suspensión o derogación del Derecho vigente) no es capaz de anular su capacidad innovadora. Por ello, a juicio del autor, no debe aceptarse la rígida distinción, trazada tanto por la doctrina como por la jurisprudencia, entre abrogación y modificación, por un lado, y suspensión y derogación provisional, por otro.

16 Otras modalidades de que cese el estado de excepción pueden ser el retiro del acto por parte del Gobierno y la devolución del mismo por parte del Presidente de la República al momento de su emisión. Ambas hipótesis, aunque difíciles de verificar, no parecen estar en conflicto irreductible con la ley fundamental. En cuanto al retiro del decreto-ley por parte del mismo órgano que lo adoptó, no hay motivos para negarlo, tanto porque no excluiría la posibilidad de que las Cámaras hagan valer la responsabilidad política, como porque en todo caso el Gobierno — si existieran las condiciones — podría adoptar un decreto derogando el anterior (Contra cfr. Paladin, Decreto-legge, en Noviss. Dig., cit. pp. 291-292, según el cual el art. 77 de la Constitución establece estrictamente los únicos hechos que pueden afectar la eficacia del acto). Con respecto a la facultad presidencial de devolución, indudablemente debería ejercerse con extrema cautela, sin perjuicio de que el Jefe de Estado podría negarse, incluso definitivamente, a dictar un decreto-ley que constituya uno de los delitos de atentado a la Constitución u otra traición (Contra cfr. CicCONETTI, Il potere di ritiro nel procedimento di formazione delle leggi, en Riv. Trim. Dir. Pubbl., 1965, pp. 397 y ss.; sobre ambas tematicas, v. CiauRro y Posteraro, Decreto-legge e legge di conversione, en Decreto legge e suoi aspetti problematici, cit., paga. 124 y ss. y pp. 144 y ss.). 
de esta manera, el cese del estado de emergencia es automático y no hay — como en la emergencia bélica - un sujeto que tenga la potestad y la responsabilidad de constatar la sobrevenida falta de necesidad ${ }^{17}$.

Vencido el plazo establecido en la Constitución, el decreto-ley, en todo caso, queda sin eficacia. Como es sabido, existen tres posibles desarrollos en la situación jurídica que se deriva del uso del decreto de urgencia: la denegación de conversión, la falta de conversión o la conversión en ley por parte de las asambleas representativas. Al ocurrir las dos primeras hipótesis, es el mismo artículo 77 de la Constitución el que conecta a estos supuestos el efecto jurídico de la pérdida de eficacia ex tunc. En la tercera hipótesis, ya sea que se adhiera a la interpretación según la cual la ley de conversión opera una novación de la fuente legal al reemplazar el decreto con efecto retroactivo ${ }^{18}$, o que se asuma el carácter ilegal del decreto-ley ${ }^{19}$, este último ya no podrá expresar ninguna capacidad calificativa de los supuestos concretos.

La referencia expresa del art. 77 a la naturaleza provisional del instrumento extraordinario sirve para conferir al Gobierno un poder dotado de fuerza cronológicamente delimitada (la temporalidad en el an), pero también para predeterminar el momento exacto en que debe cesar el ejercicio extraordinario de la fuerza de la ley (la temporalidad en el cuándo) así como el alcance retroactivo del cese de la eficacia (el quomodo de la provisionalidad o precariedad) ${ }^{20}$.

17 En otras palabras, en la máxima emergencia constitucional, el tránsito al carácter jurídico extraordinario (del estado de paz al de guerra) tiene su propia estabilidad porque, para restablecer las competencias ordinarias, es necesario volver sobre el procedimiento previsto en el art. 78 (resolución parlamentaria de cese del régimen de guerra y revocación de los poderes necesarios del Gobierno, así como declaración de cese por parte del Presidente de la República). Por lo contrario, en la situación de emergencia prevista por el art. 77 de la Constitución, la interrupción del carácter jurídico ordinario se recompone sólo por el paso del tiempo y en ausencia de una manifestación específica de voluntad.

18 V., en primer lugar, Paladin, Commento all'articolo 77, cit., pp. 82 y ss., que evidencia que la idea de que las leyes de conversión tengan el efecto de sustituir la fuente de las medidas provisionales del Gobierno se revela llena de motivos de ambigüedad, aún presentes entre los intérpretes del artículo en cuestión (mientras que algunos consideran oportuno estabilizar los efectos causados o que pueden ser causados por los decretos-leyes, otros plantean la hipótesis de una verdadera transformación de estos actos en leyes formales). El autor, que en un primer momento apoyó el funcionamiento ex tunc de la ley de conversión (PALADIN, In tema di decreti-legge, en Riv. Trim. Dir. Pubbl., 1958, pp. 567-568), está convencido de la ocurrencia de un fenómeno de sustitución y no de superposición de un acto a otro, que mantiene firmes los respectivos ámbitos temporales de eficacia.

19 La referencia es a los escritos antes mencionados de Esposito y Sorrentino. Este último (SorRENTINO, Le fonti del diritto, cit., p. 74) afirma que la ley de conversión debe calificarse «no sólo como un acto que, en sustitución del decreto-ley, sustituye la fuente de las disposiciones correspondientes, sino como un instrumento necesario para restablecer el orden de competencias violado, mediante la transformación del decreto del Gobierno en ley».

20 C. Esposito, Decreto-legge, cit., pp. 844-845, parece compartir la posibilidad de fundamentar más nociones de provisionalidad en el artículo 77: considera que de la decisión de que las medidas del Gobierno son provisionales se pueden dar dos interpretaciones: que la provisionalidad se refiera al acto mismo o que la provisionalidad se refiera al contenido del acto, es decir, «a las normas, reglas, prescripciones en él formuladas». En esta opinión autorizada, la tesis de que lo provisional no es el acto sino su contenido debería «rechazarse» porque los decretos-leyes «se denominan provisionales porque su destino es transformarse en otra cosa, 
Se ha dicho que la facultad de emanar los decretos de urgencia es autoactivada por el Gobierno, que también tiene la facultad de formular el juicio de necesidad. Sin embargo, esta activación y el juicio de necesidad del Gobierno se someten inmediatamente al control parlamentario: las Cámaras, en el curso de la conversión, deben primero verificar la «constitucionalidad» del uso del decreto-ley.

El Parlamento, una vez establecido el estado de excepción, tiene que: a) emitir su parecer sobre la existencia de uno de los «casos extraordinarios»; b) verificar la inadecuación del Derecho vigente para contener los efectos antijurídicos del evento de emergencia y la necesidad de activar recursos normativos extraordinarios; c) verificar la necesidad-adecuación de las concretas medidas de emergencia; d) decidir si extender la validez de la normativa extraordinaria a un momento posterior; e) evaluar la persistencia del vínculo fiduciario con el órgano ejecutivo.

Pasando al contenido del estado de excepción basado en el art. 77 de la Constitución, debemos partir de la premisa de que —al igual que el estado de guerra- se presenta como un subsistema de la emergencia, incluido en el sistema jurídico general, que se mantiene vigente y eficaz en todas las partes no suspendidas expresamente o derogadas provisionalmente. De hecho, el decreto-ley puede contener no solo disposiciones (medidas) específicas y concretas, sino también verdaderas normas, que pueden ser directamente prescriptivas o conferir competencias extraordinarias adicionales.

La última cuestión a examinar con respecto al instrumento de emergencia general se refiere a los límites que, según la clasificación propuesta en el «modelo abstracto», son de tres tipos: límites internos, límites explícitos y límites implícitos.

La categoría de los límites internos se basa en el mantenimiento del nexo de justificación (necesidad) entre las medidas de emergencia y el evento de emergencia para el que se adoptan. La función del poder y del acto que es expresión del mismo es remediar a la inadecuación del Derecho existente, evitando el perjuicio de posiciones jurídicas ya reconocidas. Por eso, el decreto-ley no puede: 1) tener vigencia por más de sesenta días desde la publicación del acto, ni siquiera a través de ese mecanismo de reiteración de las medidas (mediante la formación de «cadenas» de decretos-leyes) sobre cuya inconstitucionalidad se ha pronunciado la Corte constitucional de manera definitiva, con la nota sentencia n. 360 de 1996 (límite temporal); 2) tener eficacia más allá del territorio directamente implicado por los «casos extraordinarios» (límite espacial), o en supuestos concretos distintos de los

es decir, en ley desde el principio o perder su eficacia desde el principio. Las disposiciones que nacen del acto, en cambio, en cuanto aspiran a ser confirmadas o mantenidas vivas por el acto de conversión, no son provisionales, sino, según su vocación, definitivas». Esta última opinión, que tiende a limitar la provisionalidad al solo acto, no parece poder ser compartida ya que precisamente porque las normas «aspiran a confirmarse» es evidente que, hasta tal «confirmación», están dotadas de eficacia provisional. La diferencia entre acto y contenido, entonces, debería establecerse en el sentido de que — sin perjuicio de la provisionalidad de ambos-si bien el acto debe desaparecer en todo caso, su contenido puede volverse definitivo, pero sólo después del fin del estado de emergencia. Sin embargo, mientras dure la fase excepcional, también las disposiciones del decreto-ley son intrínsecamente provisionales o, en palabras de Esposito, «de validez incierta». 
directamente afectados por ellos (límite de objeto). Estos dos tipos de límites se violarían abiertamente en presencia de disposiciones que contuvieran las medidas más dispares, de las cuales solo algunas vinculadas a la ocurrencia del caso extraordinario (los denominados decretos ómnibus); 3) afirmar intereses y valores distintos de los normalmente reconocidos por el Derecho vigente, más que meramente reafirmar, con instrumentos extraordinarios, intereses y valores ordinarios (límite de contenido). La tipología que se ha presentado en la práctica que, por definición, se opone al límite de contenido es la de los llamado decretos de reforma, ya examinada.

En segundo lugar, encontramos las limitaciones que recae sobre el decreto-ley directamente de la norma que atribuye la competencia extraordinaria (límites explícitos): esta norma, como fuente de legitimación del poder, no puede ser derogada ni suspendida por el decreto, ni siquiera mediante interpretaciones extensivas o aplicaciones analógicas. Según el artículo 77 de la Constitución, el poder de emanar decretos no puede:

I) ejercerse por sujetos distintos del Consejo de Ministros ${ }^{21}$ y en particular por Ministros individuales, por el Jefe de Estado, por autoridades administrativas o militares, o por órganos de las Regiones ${ }^{22}$ (límite subjetivo). Se trata de aquella reserva de decreto-ley en casos extraordinarios de necesidad y urgencia que hemos identificado en las páginas precedentes y que convierte en ilegítimas todas las regulaciones que atribuyen, a sujetos distintos del Gobierno en su colegialidad, potestades normativas de urgencia, susceptibles de derogar la ley ordinaria ${ }^{23}$;

21 Respecto de la posición del Gobierno en curso de dimisiones o a la espera de la confianza, se debe considerar que tiene derecho a recurrir al decreto de emergencia de la misma forma que el gobierno en la plenitud de sus poderes. En este sentido, no debemos perder de vista el carácter de emergencia del instituto, cuya función es preservar valores e intereses que ya reciben reconocimiento jurídico: de esta manera, la adopción de un decreto-ley no tiene nada que ver con la realización del programa de gobierno (actividad que no puede ser ejercida por el gobierno que dimite o espera la confianza). Entonces, las perplejidades que se han planteado no parecen referirse al instrumento de emergencia previsto por el art. 77 de la Constitución, sino al mismo instrumento según ha sido tergiversado por su aplicación práctica: si el decreto-ley se convierte en un instrumento ordinario para la producción del Derecho, el Gobierno efectivamente en pleno ejercicio de sus poderes "para asuntos corrientes», debería abstenerse de utilizarlo.

22 Sobre la admisibilidad de los decretos-leyes regionales, en ausencia de una disposición específica que atribuya esa competencia, no parece que el artículo 77 pueda extenderse por analogía al Consejo Regional. Lo que se puede admitir es que el órgano ejecutivo del ente territorial pueda sustituirse al Consejo en la adopción de medidas administrativas, sin perjuicio de la posterior ratificación de este último. En este sentido puede verse Ciaurro, Decreto legge, cit., p. 7; Di Ciolo, Questioni in tema di decreti-legge, cit., pp. 96 y ss.; C. Esposito, I decreti-legge delle Regioni, en Giur. Cost., 1959, pp. 780 y ss.; C. LAVAGNA, Inammissibilità dei decreti-legge regionali, in Studi in onore di Crosa, II, Milano 1960, pp. 1095 y ss.; STIPO, I decreti legge nell'ordinamento regionale, in Decreto legge e suoi aspetti problematici, cit., pp. 227 y ss., quien considera que los actos legislativos regionales, distintos de la ley, a los que se refiere el art. 134 de la Constitución podrían ser «los actos improrrogables» expedidos por la Comisión de tres ciudadanos prevista en el art. 126 de la Constitución, en caso de disolución del Consejo Regional. Contra v. V. CRISAfulli, Sull'ammissibilità dei decreti legge regionali, en Rass. Parl., 1959, VIII-IX, pp. 9 y ss.

23 La referencia es a las ordenanzas de necesidad. Estas medidas «administrativas», que pueden llegar a derogar la ley y tener que respetar sólo los principios generales del ordenamiento jurídico, hasta el 1992 
II) ejercerse según un procedimiento distinto al establecido en la Constitución como, por ejemplo, desatendiendo la existencia del presupuesto, omitiendo la presentación «el mismo día» a las Cámaras o fijando un plazo de conversión mayor o menor al legal (limite del procedimiento); III) ejercer competencias - por naturaleza, contenido y fuerza - distintas a las contempladas por la norma que confiere el poder (límite de la competencia). De esta forma, el decreto-ley no puede intervenir en materia jurisdiccional o intervenir, tras la negativa a convertir decretos anteriores, ya sea renovando las disposiciones contenidas en dichos decretos, ya sea regulando las relaciones jurídicas que se deriven de ellas ${ }^{24}$. En tercer lugar, la fuente gubernamental no puede ejercer una fuerza mayor que la de la ley ordinaria ${ }^{25}$, por ejemplo, suspendiendo o derogando derechos fundamentales o el sistema de atribuciones constitucionales.

Finalmente encontramos los límites implicitos, o aquellas limitaciones de la potestad de decreto urgente que se basan en una lectura sistemática de otras disposiciones constitucionales que el artículo 77 demuestra presuponer. De esta forma, la doctrina que se ha ocupado del estudio del decreto de emergencia considera que el Gobierno no podría sustituirse al Parlamento en aquellas actividades que estén específicamente dirigidas al control del ejecutivo o que en cualquier caso postulen la alteridad de los dos sujetos de la relación fiduciaria ${ }^{26}$. Básicamente receptivo de esta interpretación —añadiendo los límites deducibles del mismo art. $77^{27}$ y excluida la materia electoral ${ }^{28}$ - el art. 15.1 de la ley n. ${ }^{\circ} 400$

estaban previstas por regulaciones (art. 2 del T.u.l.p.s. y art. 20 del T.u.l.c.p.) anteriores a la entrada en vigor de la Constitución; estas regulaciones fueron consideradas sustancialmente legítimas por la Corte constitucional (véanse sentencias n. ${ }^{\circ} 8$ de 1956, n. $^{\circ} 26$ de 1961, n. ${ }^{\circ} 4$ de 1977 y n. ${ }^{\circ} 201$ de 1987). Posteriormente la ley n. ${ }^{\circ} 225$ de 1992 (Establecimiento del servicio nacional de protección civil) reguló otro poder de ordenanza del Gobierno y de los Prefectos sujeto a la declaración del estado de emergencia; también esta regulación, aunque enjuiciada en ocasión de un conflicto de atribuciones entre el Estado y Región, fue considerada por la Corte constitucional compatible con la ley fundamental (sentencia n. ${ }^{\circ} 127$ de 1995).

24 Para un reconocimiento expreso de esta prohibición, ver el art. 15 de la ley n. ${ }^{\circ} 400$ de 1988.

25 Es oportuno recordar que el Comité de coordinación eliminó del texto del proyecto (artículo 74) el adjetivo «ordinario» que, para evitar dudas, introdujo la enmienda Codacci Pisanelli para calificar la fuerza de las medidas gubernamentales. Cabe agregar que, sin embargo, la lectura de los trabajos en Asamblea Constituyente (Atti Ass. Cost., 16 y 17 de octubre de 1947, pp. 1293 y ss.) no deja lugar a dudas sobre la intención de equiparar la fuerza de los decretos con el de las leyes ordinarias. En este sentido, la supresión del adjetivo parece animada por el deseo de eliminar una expresión reiterativa, en tanto que evidente.

26 De esta opinión, casi textualmente, Sorrentino, Le fonti del diritto, cit., pp. 82-83.

27 Nos referimos a los puntos señalados con las letras c) y d) que se fundan directamente en la norma de atribución de competencia (primera y segunda parte del tercer párrafo del artículo 77 de la Constitución) y que por ello hemos incluido entre los límites jurídicos explícitos.

28 Quizás debería hacerse una excepción respecto de la referencia contenida en el art. 72.4 de la Constitución, en la parte en la que establece el límite de la «materia electoral»: esta limitación no parece tener ningún fundamento en disposiciones constitucionales y surge de consideraciones de conveniencia política, por las que es desaconsejable, en el periodo previo a la consulta electoral, que una de las partes involucradas (la mayoría) altere las reglas del juego. Sin embargo, debe recordarse que la ratio adicional de la prohibición se 
de 1988 establece que el Gobierno no puede, por decreto-ley: a) conferir delegaciones legislativas; b) regular las materias señaladas en el art. 72.4 de la Constitución; c) renovar las disposiciones de los decretos cuya conversión haya sido denegada por el voto de una de las dos Cámaras; d) regular las relaciones que surjan sobre la base de decretos no convertidos; e) restablecer la eficacia de las disposiciones declaradas ilegítimas por la Corte constitucional por vicios ajenos al procedimiento.

Cada una de estas prohibiciones tiene una base constitucional indirecta: en el art. 76 se encuentra la prohibición de la autodelegación legislativa, en el art. 138 (así como el propio art. 77) aquella para innovar en materia constitucional y en el art. 136 la prohibición de restablecer la eficacia de las disposiciones declaradas ilegítimas por el Juez de leyes. Sin perjuicio de estos anclajes textuales, el núcleo lógico-jurídico de las fronteras que el art. 15 de la ley n. ${ }^{\circ} 400$ de 1988 traza está, en última instancia, representado por la forma de gobierno parlamentaria: admitir el recurso al decreto en esos casos equivaldría a alterar el sistema de distribución de los poderes soberanos, contradiciendo tanto las prescripciones concretas, como los principios de la Constitución vigente.

\section{El empleo del endeudamiento extraordinario previsto en el art. 81 de la Constitución}

Respecto de la emergencia sanitaria provocada por el Covid-19, es útil examinar brevemente un segundo estado de excepción introducido en la Constitución por la ley de revisión constitucional n. ${ }^{\circ} 1$ de 2012 y regulado en la ley ordinaria «reforzada» n. ${ }^{\circ} 243$ de 2012.

Según el nuevo art. 81 de la Constitución, en cumplimiento de lo dispuesto en el tratado de Fiscal Compact ${ }^{29}$ : «El Estado asegura el equilibrio entre los ingresos y los gastos de su presupuesto, teniendo en cuenta las fases adversas y favorables del ciclo económico».

En el siguiente párrafo se dispone que: «El recurso a la deuda se permite sólo con el propósito de considerar los efectos del ciclo económico y, tras la aprobación de las Cámaras con mayoría absoluta de los respectivos miembros, en caso de eventos excepcionales» ${ }^{30}$.

encuentra en la naturaleza irreversible de los efectos del decreto-ley en materia electoral (v. M. AINIS, Gli effetti irreversibili del decreto legge, ahora en Le parole e il tempo della legge, op. cit., pp. 200-202). De todos modos, no parece posible excluir situaciones en las que el recurso al decreto de urgencia resulte legítimo y necesario (por ejemplo, ante la ocurrencia de un desastre natural durante el período electoral, puede ser «necesario» posponer la votación o fijar modalidades especiales de ejecución).

29 El Tratado de Estabilidad, Coordinación y Gobernanza en la Unión Económica y Monetaria fue firmado en Bruselas en febrero de 2012.

30 El resto del artículo establece que: «Toda ley que imponga cargas nuevas o mayores proporciona los medios para hacerles frente. / Cada año las Cámaras aprueban por ley el presupuesto y la cuenta final que 
Por tanto, el equilibrio presupuestario es, en condiciones normales, un objetivo a alcanzar y mantener, teniendo en cuenta las fases adversas y desfavorables del ciclo económico. En cambio, «en caso de hechos excepcionales», es posible derogarlos temporalmente recurriendo a una deuda extraordinaria. Corresponde a una ley ordinaria aprobada por mayoría absoluta ${ }^{31}$ definir los hechos extraordinarios que legitiman la derogación extraordinaria, así como las modalidades, los poderes y los límites de la declaración del estado de excepción. El art. 6 de la ley n. ${ }^{\circ} 243$ de 2012 establece que «las desviaciones provisionales del saldo estructural del objetivo programático sólo se permiten en caso de eventos excepcionales». Entre los eventos excepcionales se pueden identificar dos categorías de situaciones: a) «períodos de grave recesión económica relacionados también con la zona del euro o con toda la Unión Europea»;

b) «circunstancias extraordinarias, ajenas al control del Estado, que incluyen tanto crisis financieras graves como desastres naturales graves, con repercusiones importantes en la situación financiera general del país».

La primera tipología incluye eventos extraordinarios de carácter económico que conducen a una grave depresión en las tasas de productividad, del empleo y al aumento de los precios. La gran conexión e integración entre los sistemas económicos de los Estados miembros hace pensar que es necesaria la participación de todo el sistema europeo.

El segundo caso, en cambio, se refiere a hechos extraordinarios de naturaleza no necesariamente económica pero que tienen efectos indirectos sobre la situación financiera del país. Es, por tanto, una tipología más indeterminada que la primera, capaz de legitimar el uso del estado de excepción ante desastres naturales, desastres ambientales, inmigración masiva, conflictos militares.

Ante uno de estos presupuestos, el Gobierno, si «considera imprescindible apartarse temporalmente del objetivo programático» para hacer frente a tales circunstancias, previa consulta a la Comisión Europea, presenta a las Cámaras «una solicitud específica de autorización». Esta petición debe indicar el alcance y la duración de la desviación, los propósitos para los cuales asignar los recursos disponibles y el plan de retorno hacia el objetivo programático. La resolución mediante la cual cada Cámara autoriza la desviación y aprueba el plan de retorno «se adopta por mayoría absoluta de los respectivos miembros».

Este procedimiento también se aplica «si el Gobierno tiene la intención de recurrir a la deuda para realizar operaciones relacionadas con partidas financieras con el fin de hacer frente a eventos extraordinarios».

presenta el Gobierno. / El ejercicio provisional del presupuesto no podrá concederse salvo por ley y por períodos que no excedan los cuatro meses. / El contenido de la ley de presupuesto, las reglas y criterios fundamentales destinados a asegurar el equilibrio entre los ingresos y los gastos presupuestarios y la sostenibilidad de la deuda del conjunto de las administraciones públicas se establecen mediante ley aprobada por mayoría absoluta de los miembros de cada Sala, en cumplimiento de los principios definidos por ley constitucional».

31 Como establecido por el citado último párrafo del art. 81 de la Constitución. 
Recordando las categorías que se han expuesto, podemos decir que la ley n. ${ }^{\circ} 243$ dispone un estado de excepción económica que debe establecerse expresamente: el Gobierno tiene el poder de iniciativa, que tiene que ser considerada reservada a ese órgano, y las Cámaras tienen el poder de autorizar la derogación de la restricción presupuestaria y/o recurrir a la deuda extraordinaria. Por tanto, corresponde conjuntamente a las dos ramas del Parlamento abrir el estado de excepción mediante una decisión adoptada por la mayoría de los miembros.

Tenemos por tanto una hipótesis de «hetero-activación», pues el juicio sobre la ocurrencia del presupuesto legitimador y la declaración expresa del estado de excepción se atribuyen a un órgano diferente (Parlamento) respecto del que se beneficiará de la competencia extraordinaria (el Gobierno).

El estado de excepción que así se establece parece respetuoso de los límites inherentes a los regímenes de emergencia ya que el acto parlamentario debe establecer la duración temporal del régimen, identificar el alcance y la duración del apartamiento del régimen general, los fines para los cuales destinar los recursos disponibles, y también el plan de retorno hacia el objetivo programático y por tanto el cierre del régimen excepcional.

\section{Poder de dictar órdenes previsto en la legislación ordinaria}

El último estado de excepción que debe examinarse para evaluar la legitimidad de las decisiones tomadas para hacer frente a la epidemia de Covid-19 es el poder administrativo de emitir órdenes u ordenanzas. En efecto, más allá de las normas que confieren poderes extraordinarios contenidas en la Constitución (artículos 77, 78, 81 y 126), el ordenamiento italiano prevé un poder de emergencia adicional que asigna a algunos órganos administrativos la facultad de adoptar ordenanzas en derogación del Derecho vigente para hacer frente a situaciones de emergencia. Se trata de numerosas disposiciones a nivel legislativo ${ }^{32}$ que regulan de forma heterogénea y esporádica un poder —en su conjunto - con contornos indefinidos en cuanto a presupuestos legitimadores, sujetos titulares, naturaleza y contenido de la competencia ${ }^{33}$.

32 La única excepción está representada —en el contexto regional- por el art. 88 (ubicado en el Título VII dedicado a las «Relaciones entre Estado, Región y Provincias») del Estatuto de Trentino Alto Adige según el cual «El Comisario del Gobierno se ocupa del mantenimiento del orden público, por lo que responde al Ministro del Interior. Para ello podrá hacer uso de los cuerpos y fuerzas policiales del Estado, solicitar el uso de otras fuerzas armadas en los términos de las leyes vigentes y adoptar las medidas previstas en el art. 2 del Texto Único de las Leyes de Seguridad Pública. Siguen vigentes las atribuciones que le confieren las leyes vigentes al Ministerio del Interior».

33 Habla de la naturaleza «polimórfica» del poder de ordenanza, F. BARTOLOMEI, Potere di ordinanza e ordinanze di necessità, Milano 1979, pp. 54 y también 62 y ss, señalando que pueden darse tanto la circunstancia de que un mismo organismo pueda ser beneficiario de diferentes tipos de competencias, como que existan diferentes formas de ejercicio del poder de ordenanza, y que — se puede añadir — en ocasiones se establezcan 
Entre las ordenanzas de necesidad, podemos identificar diferentes tipologías en base a tres criterios de clasificación: el nivel de las disposiciones sujetas a suspensión o derogación provisional, los presupuestos legitimadores que establece la norma que confiere la competencia para la adopción de las ordenanzas y el grado de predeterminación del contenido por parte de la misma norma atributiva.

En base al primer criterio, tenemos las medidas que cumplen con el criterio jerárquico de preferencia de la ley (órdenes administrativas en sentido estricto) o las que actúan «en derogación de cualquier disposición vigente» (ordenanzas en derogación de la ley). Sobre la base del segundo tenemos las ordenanzas generales, capaces de contrarrestar hechos de emergencia no identificados y las ordenanzas especiales, que se prevén para emergencias típicas. Finalmente, podemos distinguir el caso en el que el contenido es determinado concretamente por el sujeto titular del poder extraordinario (con contenido libre) del caso en el que la ley predetermina, más o menos detalladamente, las medidas de emergencia que pueden adoptarse (con contenido vinculado).

Dado que este no es el lugar para un examen analítico de los diferentes tipos de ordenanzas que se rigen por la ley italiana, es suficiente examinar los tipos utilizados principalmente por el Gobierno italiano, pero también por las Regiones y Municipios, a partir de marzo de 2020 para tratar las Epidemia de Covid-19.

Dado que este no es el contexto adecuado para un examen analítico de los diferentes tipos de ordenanzas reguladas por el Derecho italiano ${ }^{34}$, basta con examinar los tipos utilizados principalmente por el Gobierno italiano, pero también por las Regiones y los Municipios, a partir de marzo de 2020 para combatir la epidemia del Covid-19.

La regulación más importante está representada por el Código de Protección Civil, esto es, el decreto legislativo $1 / 2018^{35}$, que organiza un sistema de respuesta rápida ante «emergencias conexas con desastres de origen natural o derivados de la actividad humana» (art. 7). Este sistema depende del Presidente del Consejo de Ministros y del Departamento de Protección Civil de la Presidencia del Consejo e incluye tanto a órganos estatales (Gobierno, Prefectos, Cuerpo nacional de Bomberos, Fuerzas Armadas, Fuerzas Policiales, Servicio Nacional de Salud y otras organizaciones), como órganos del gobierno local (Regiones y Municipios). El art. 24, ante la ocurrencia de una emergencia de protección civil, asigna al Consejo de Ministros, a propuesta del Primer Ministro, la facultad de deliberar sobre el «estado de emergencia de importancia nacional», estableciendo su duración y determinando su extensión territorial y autorizando el recurso al poder de orde-

poderes de ordenanza primarios para algunos órganos (por ejemplo, el Alcalde) y subsidiarias en manos de otros (por ejemplo, el Prefecto).

34 V. G. Marazzita, Il conflitto tra autorità e regole: il caso del potere di ordinanza, en Rivista dell'Associazione Italiana dei Costituzionalisti n. $^{\circ} 4$ de 2010, pp. 1-48.

35 El código incorpora y reorganiza la regulación originalmente introducida por la ley n. ${ }^{\circ} 225$ de 1992 y posteriormente objeto de cambios legislativos e intervenciones jurisdiccionales. 
nanza $^{36}$. El art. 25 regula la consiguiente potestad de ordenanza al establecer que «para la coordinación de la ejecución de las intervenciones que se realicen durante un estado de emergencia de importancia nacional, se actuará a través de ordenanzas de protección civil, que se adoptarán en derogación de cualquier disposición vigente ${ }^{37}$. La regla de atribución prevé expresamente el alcance antinómico ${ }^{38}$ respecto de cualquier disposición vigente, excepto el cumplimiento de los «principios generales del ordenamiento jurídico», cuyo carácter inderogable ha sido identificado por la Corte constitucional desde 1956.

En cuanto a la titularidad del poder, corresponde al Presidente del Consejo de Ministros, salvo que se establezca otra cosa en la resolución del Consejo de Ministros sobre el estado de excepción nacional ${ }^{39}$. El acto de ejercicio del poder es el Decreto del Presidente del Consejo de Ministros (D.P.C.M.).

En cuanto al contenido, las ordenanzas de protección civil deben estar motivadas, pero son del tipo «libre» porque se reconoce una amplia discreción de la autoridad administrativa en la determinación de las medidas de emergencia ya que estas no están, de ninguna manera, tipificadas por la fuente primaria.

Un segundo poder que permite emanar ordenanzas, relevante en la emergencia provocada por el Covid-19, es el que se atribuye al Ministro de Salud por el

36 Según el art. 24 del Decreto Legislativo n. 1 de 2018 «Ante la ocurrencia de hechos que, tras una pronta evaluación realizada por el Departamento de Protección Civil en base a los datos e información disponible y en conjunto con las Regiones y Provincias Autónomas interesadas, presenten los requisitos a los que se refiere el artículo 7.1, letra c), o en su inminencia, el Consejo de Ministros, a propuesta del Presidente del Consejo de Ministros, también a petición del Presidente de la Región o Provincia Autónoma de que se trate y en todo caso habiendo llegado a un acuerdo, declara el estado de emergencia de importancia nacional, estableciendo su duración y determinando su extensión territorial con referencia a la naturaleza y cualidad de los hechos y autoriza la expedición de las ordenanzas de protección civil a que se refiere el artículo 25. La resolución identifica, de acuerdo con los criterios homogéneos definidos en la directiva mencionada en el apartado 7 , los primeros recursos financieros que se destinarán al inicio de las actividades de rescate y asistencia a la población y a las intervenciones más urgentes a las que se refiere el artículo 25.2, letras a) y b), a la espera del reconocimiento de las necesidades reales, y autoriza el gasto con cargo al Fondo para las emergencias nacionales al que se refiere el artículo 44».

37 El art. 25 del Decreto Legislativo n. ${ }^{\circ} 1$ de 2018 establece: «Para la coordinación de la ejecución de las intervenciones a realizarse durante el estado de emergencia de importancia nacional, se actúa a través de ordenanzas de protección civil, que se adoptarán en derogación de cualquier disposición existente, dentro de los límites y con las modalidades indicados en la decisión del estado de emergencia y de conformidad con los principios generales del ordenamiento jurídico y las normas de la Unión Europea. Las ordenanzas se dictan una vez obtenido el acuerdo de las Regiones y Provincias autónomas territorialmente interesadas y, en caso de que den lugar a derogaciones de las leyes vigentes, deben contener una indicación de las principales normas a las que se pretende derogar y deben ser específicamente motivadas».

38 Sobre la capacidad innovadora de las ordenanzas, ver SEvERI, Le ordinanze della legge n. 225/92 sulla protezione civile, Milano, 1996, p. 14.

39 Según el art. 5 del Decreto Legislativo n. ${ }^{\circ} 1$ de 2018 «El Presidente del Consejo de Ministros, para la consecución de los fines del Servicio Nacional, ostenta los poderes de ordenanza en materia de protección civil, que podrá ejercitar, salvo que se establezca lo contrario con la resolución a la que se refiere el artículo 24, a través de la actuación del Jefe del Departamento de Protección Civil, y determina las políticas de protección civil para la promoción y coordinación de las actividades de las administraciones del Estado, centrales y periféricas, de las regiones, ciudades metropolitanas, provincias, municipios, entidades públicas nacionales y territoriales y cualesquiera otra institución y organización público o privado presente en el territorio nacional». 
art. 32 de la Ley del Servicio Nacional de Salud (ley 833/1978), según la cual el titular del Ministerio «puede dictar órdenes de carácter contingente y urgente, en materia de higiene y salud pública o policía veterinaria, con eficacia extendida a todo el territorio nacional o parte de él que incluyan varias Regiones». Este tipo de ordenanza, además de no tener límites específicos en cuanto al contenido, tiene un alcance general, aunque solo en materia de salud.

El tercer párrafo del mismo art. 32, para emergencias sanitarias en el ámbito local, establece que «En las mismas materias, las órdenes de carácter contingente y urgente son dictadas por el Presidente del Consejo regional y por el Alcalde, con efecto extendido respectivamente a la región o a parte de su territorio que incluya varios municipios y al territorio municipal». También en el caso de ordenanzas regionales y municipales, ese poder tiene alcance general en materia de salud y no tiene límites de contenido.

Por último, cabe señalar que, de acuerdo con el art. 117 del Decreto Legislativo 112/1998 (Concesión de funciones y tareas administrativas del Estado a las Regiones y órganos locales), «En caso de emergencias sanitarias o de higiene pública de carácter exclusivamente local, el Alcalde, en representación de la comunidad local, adoptará las órdenes de carácter contingente y urgente. En los otros casos, la adopción de medidas de urgencia, incluyendo el establecimiento de centros y organismos de referencia o asistencia, corresponde al Estado o a las Regiones en razón de la magnitud de la emergencia y de la posible afectación de varios ámbitos territoriales regionales ${ }^{40}$. Dado que es obvio que la pandemia en curso no tiene carácter «exclusivamente local», esta regla de atribución no es irrelevante.

\section{LOS ACTOS NORMATIVOS Y ADMINISTRATIVOS ADOPTADOS PARA HACER FRENTE A LA EPIDEMIA PROVOCADA POR EL COVID-19 DESDE ENERO DE 2020}

Ahora que se ha definido el modelo «positivo» de la emergencia jurídica regulado por el Derecho vigente, es posible pasar a la tercera y última fase de nuestro análisis para reconstruir el «modelo concreto» de estado de excepción instaurado en los años 2020-2021 para hacer frente a la pandemia viral.

En primer lugar, es necesario examinar los actos normativos y administrativos adoptados en la práctica a partir de enero de 2020 para enfrentarse a la crisis epidémica. Se trata de una «cadena normativa» de la que es necesario examinar, aunque sea brevemente, los principales componentes en orden cronológico.

40 En el siguiente párrafo se afirma que: «En caso de emergencia que afecte el territorio de varios municipios, cada Alcalde adoptará las medidas necesarias hasta que intervengan los sujetos competentes de conformidad con el párrafo $1 »$. 
El acto introductorio de la fase extraordinaria está representado por la resolución del Consejo de Ministros de 31.1.2020 que, basándose también en la declaración de «emergencia internacional de salud pública» por el coronavirus (PHEIC) de la Organización Mundial adoptada el día anterior ${ }^{41}$, declaró «durante 6 meses a partir de la fecha de esta disposición, el estado de emergencia como consecuencia del riesgo sanitario conexo con la aparición de patologías derivadas de agentes virales transmisibles».

El acto — cuya base legal es el art. 24 del Código de Protección Civil (Decreto Legislativo 1/2018) — establece que, para la ejecución de las primeras intervenciones $^{42}$, «se actúe con ordenanzas, emitidas por el Jefe del Departamento de Protección Civil en derogación de cualquier disposición vigente y en cumplimiento de los principios generales del ordenamiento jurídico». Al mismo tiempo, se autoriza el uso de los recursos del Fondo para las emergencias nacionales.

El 11 de marzo de 2020, las Cámaras autorizaron al Gobierno a realizar la primera variación presupuestaria ex art. 81 de la Constitución y la actualización del plan de retorno hacia el objetivo de mediano plazo para atender las necesidades sanitarias y socioeconómicas derivadas de la emergencia epidemiológica.

El 23 de febrero de 2020, el gobierno italiano recurrió al poder extraordinario de emanación de decretos basado en el art. 77 de la Constitución al aprobar el decreto-ley 6/2020. En el art. 1 se establecieron una serie de medidas urgentes para evitar la propagación del COVID-19, cuya activación corresponde, según el art. 3, a «uno o más decretos del Presidente del Consejo de Ministros (DPCM), a propuesta del Ministro de Salud, previa consulta al Ministro del Interior, al Ministro de Defensa, al Ministro de Economía y Finanzas y a los otros Ministros competentes según la materia», así como a los «Presidentes de las regiones competentes, en el caso de que se refieran exclusivamente a una región o a algunas regiones concretas, o al Presidente de la Conferencia de las Regiones y Provincias Autónomas, en el caso de que afecten a todo el territorio nacional».

A mediados de marzo de 2020, tras la propagación exponencial del virus, el ejecutivo aprobó dos medidas: el decreto-ley 18/2020 (convertido por el Parlamento a través de la ley 27/2020) que contiene «Medidas para fortalecer el servicio nacional de salud y para el apoyo económico a las familias, los trabajadores y las empresas»; el decreto-ley 19/2020 (convertido por el Parlamento a través de la ley de conversión 35/2020), en cambio, prevé una serie de «Medidas urgentes para hacer frente a la emergencia epidemiológica por COVID-19» (limitaciones a la libertad de circulación, cierre de las actividades laborales, suspensión de las actividades didácticas) cuya activación se delegó —como en

41 El mismo, el Ministro de Salud con su propia ordenanza «prohibió el tráfico aéreo desde China, como país que incluye áreas en las que se ha producido una fuerte transmisión autóctona del nuevo Coronavirus $(2019-\mathrm{nCoV}) »$.

42 Nos referimos a las intervenciones ex artículo 25.2 , letras a) y b) del Decreto Legislativo n. ${ }^{\circ} 1$ de 2018. 
el caso del decreto-ley 6/2020 - al D.P.C.M. a propuesta del Ministro de Salud. El Ministro de Salud y las Regiones «En tanto no se adopten los decretos del Presidente del Consejo de Ministros (...) y con eficacia limitada hasta ese momento, en casos de extrema necesidad y urgencia por situaciones inesperadas» pueden actuar de manera autónoma en aplicación de sus propios poderes. Asimismo, el decreto-ley establece sanciones administrativas (y no penales) para los casos de violación de las medidas.

En abril se aprobaron otros dos actos legislativos extraordinarios basados en el art. 77 de la Constitución: el decreto-ley 22/2020 (convertido por el Parlamento a través de la ley n. ${ }^{\circ} 41$ de 2020) que prevé una serie de «Medidas urgentes para la conclusión regular y el inicio ordenado del año escolar y sobre la realización de los exámenes estatales», cuya ejecución se delega a las ordenanzas del Ministro de Educación; el decreto-ley 23/2020 (convertido por el Parlamento a través de la ley 40/2020), de su lado, contiene medidas económicas de aplicación inmediata «en materia de acceso al crédito y obligaciones tributarias de las empresas, de competencias especiales en sectores estratégicos, así como intervenciones en el ámbito de salud y trabajo, de ampliación de plazos administrativos y procesales»; el 10 de abril de 2020, se emanó el D.P.C.M. que creó en la Presidencia del Consejo de Ministros el «Comité de expertos en materia económica y social» que tenía la tarea de «elaborar y proponer al Primer Ministro las medidas necesarias para hacer frente a la emergencia epidemiológica COVID-19».

El decreto-ley 28/2020 (convertido por el Parlamento a través de la ley 70/2020) introdujo «Medidas urgentes para la funcionalidad de los sistemas de interceptación de conversaciones y comunicaciones, en el ámbito del sistema penitenciario, así como disposiciones complementarias y de coordinación en el ámbito de la justicia civil, administrativa y contable».

El decreto-ley 30/2020 (convertido por el Parlamento a través de la ley 72/2020) contiene «Medidas urgentes en materia de estudios epidemiológicos y estadísticos sobre el SARS-COV-2».

En mayo de 2020, tras una mejora solo temporal de la situación de emergencia, el gobierno italiano aprobó dos decretos-leyes más: el decreto-ley 33/2020 (convertido por el Parlamento a través de la ley 74/2020) con el que «todas las medidas restrictivas de la circulación dentro del territorio regional dejan de tener efecto (...) y tales medidas se podrán adoptar o reiterar (...) sólo con referencia a zonas concretas de un mismo territorio afectadas por un particular agravamiento de la situación epidemiológica». Este acto introduce el sistema de clasificación de las Regiones en grupos o niveles de riesgo y, entre los actos de ejercicio del poder de ordenanza, empiezan a asumir un papel importante las ordenanzas del Ministerio de Sanidad; el decreto-ley 34/2020 (convertido por el Parlamento con la ley 77/2020), el denominada «Decreto relanzamiento», que contiene medidas económicas para apoyar el trabajo y la economía.

Incluso ante un relajamiento de las medidas restrictivas, el Gobierno, con resolución del Consejo de Ministros de 29 de julio de 2020, prorrogó «el estado 
de emergencia como consecuencia del riesgo sanitario conexo con la aparición de patologías derivadas de agentes virales transmisibles».

El decreto-ley 83/2020 (convertido por el Parlamento a través de la ley 124/2020) contiene medidas urgentes conexas con la caducidad de la declaración de emergencia epidemiológica provocada por el COVID-19 emanada el 31 de enero de 2020 y reguló la renovación de los puestos de dirección del Sistema de Información para la seguridad de la República. El decreto-ley 104/2020 (convertido por el Parlamento a través de la ley 126/2020) introdujo «Medidas urgentes para apoyar y relanzar la economía». A principios de octubre, debido al resurgimiento de la crisis sanitaria, se aprobó el decreto-ley 125/2020 (convertido por el Parlamento a través de la ley 159/2020) para introducir «Medidas urgentes relacionadas con la prórroga de la declaración del estado de emergencia epidemiológico provocada por el COVID-19, para el aplazamiento de las consultas electorales para el año 2020 y para la continuidad operativa del sistema de alerta COVID, así como para la implementación de la Directiva (UE) 2020/739 de 3 de junio, y disposiciones urgentes sobre la recaudación de impuestos». En el mismo mes de octubre, el decreto-ley 137/2020 (convertido por el Parlamento a través de la ley 176/2020) introdujo «Otras medidas urgentes en materia de protección de la salud, apoyo a los trabajadores y a las empresas, justicia y seguridad, conexas con la emergencia epidemiológica por Covid-19». En diciembre de 2020, con el decreto-ley 172/2020 (convertido por el Parlamento a través de la Ley 6/2021), se aprobaron directamente «Otras disposiciones urgentes para hacer frente a los riesgos sanitarios asociados con la propagación del virus COVID-19».

A principios de 2021, el Gobierno, mediante Resolución del Consejo de Ministros de 13 de enero de 2021, prorrogó el «el estado de emergencia como consecuencia del riesgo sanitario conexo con la aparición de patologías derivadas de agentes virales transmisibles». Posteriormente, encontramos una serie de intervenciones normativas extraordinarias adicionales basadas en la aplicación del artículo 77 de la Constitución que, más allá de sus contenidos específicos, no modifican la estructura de poderes extraordinarios y las modalidades de activación de las medidas concretas. Por lo que concierne al «empleo de la deuda» previsto por el art. 81 de la Constitución «ante la ocurrencia de circunstancias excepcionales», el Gobierno solicitó y obtuvo seis «desviaciones presupuestarias» mediante la prevista «autorización de las Cámaras adoptada por mayoría absoluta».

Como se ha anticipado, el 5 de marzo de 2020, el Gobierno presentó el primer Informe (Relación) al Parlamento para hacer frente a las consecuencias de la epidemia y los nuevos objetivos de finanzas públicas se autorizaron por el Parlamento el 11 de marzo de 2020 para financiar las medidas contenidas en los decretos-leyes n. ${ }^{\circ} 18,23$ y 34 de 2020. Posteriormente, con motivo de la presentación del Documento Económico y Financiero (DEF) de 2020, el 24 de abril, el Gobierno presentó un segundo Informe y la segunda «variación presupuestaria» 
se autorizó los días 29 y 30 de abril para la financiación de las medidas introducidas por el decreto-ley 34/2020. El 23 de julio, el Gobierno presentó el tercer Informe al Parlamento y los nuevos objetivos de las finanzas públicas se autorizaron por el Parlamento con la aprobación del 29 de julio para la financiación de las medidas introducidas por el decreto-ley 104/2020. El 6 de octubre, en la presentación de la Nota de actualización del DEF 2020, el Gobierno envió un nuevo Informe a las Cámaras y se autorizó la cuarta «variación presupuestaria» el 14 de octubre. El 21 de noviembre, el Gobierno envió un nuevo Informe al Parlamento y la quinta «variación presupuestaria» fue autorizada por las Cámaras el 26 de noviembre. Finalmente, el 15 de enero de 2021, el Gobierno envió el sexto Informe a las Cámaras y el Parlamento aprobó la sexta autorización de deuda extraordinaria el 20 de enero.

\section{EL «MODELO CONCRETO» DE ESTADO DE EXCEPCIÓN SANITARIO INSTAURADO EN LOS AÑOS 2020-2021 Y SU CONFORMIDAD CON EL MODELO CONSTITUCIONAL}

Ahora que se ha reconstruido brevemente la secuencia de actos de gobierno y parlamentarios a través de los cuales, a partir de principios de 2020, se hizo frente a la emergencia sanitaria, es posible reconstruir el modelo concreto de estado de excepción: el objetivo será dar respuesta a la pregunta que nos planteamos en las premisas, esto es, si y de qué manera se ha aplicado y respetado la Constitución de emergencia en las distintas fases del estado de excepción provocado por el Covid-19.

En cuanto al estado de excepción relativo a las medidas restrictivas de los derechos de libertad, el esquema central a través del cual el Gobierno italiano desde el decreto-ley 6/2020 - ha gestionado la emergencia sanitaria está representado por el uso de un particular «binomio normativo» que consta de dos actos legislativos extraordinarios, con diferentes grado y funciones: el decreto-ley, fuente primaria aprobada según el art. 77 de la Constitución por el Consejo de Ministros y sujeto a conversión en ley por el Parlamento, que tiene la función de definir las medidas que limitan los derechos y libertades de los ciudadanos; el decreto del Presidente del Consejo de Ministros (D.P.C.M.), la fuente secundaria adoptada de conformidad con el decreto legislativo 1/2018 (Código de Protección Civil) con base en la declaración del «estado de emergencia nacional», con el que se tienen que adoptar e implementar concretamente las medidas de limitación previstas por la fuente primaria.

Además de estos dos instrumentos normativos estatales, el decreto-ley 6/2020 estableció que las entidades locales y las regiones «en tanto no se adopten los decretos del Presidente del Consejo de Ministros» y «en casos de extrema necesidad y urgencia» están autorizadas en aplicación de sus propios poderes de ordenanza para adoptar medidas restrictivas; tales medidas «pierden su eficacia si 
no se comunican al Ministro de Salud dentro de las veinticuatro horas siguientes a su adopción ${ }^{43}$.

A partir de lo dicho hasta ahora, parecería que existe una clara distinción entre el papel asignado a la fuente primaria (el decreto-ley) y el asignado a la fuente secundaria (D.P.C.M. u ordenanzas de la autoridad local): la primera tendría que, en cumplimiento de las reservas de ley, proporcionar medidas restrictivas, mientras que la segunda se limitaría a implementar efectivamente tales medidas.

Sin embargo, cabe señalar que el art. 1 del decreto-ley 6/2020, además de enumerar y definir una serie de medidas limitadoras específicas, contenía también una disposición general según la cual las «autoridades competentes» tienen que adoptar «todas las medidas de contención y gestión que sean adecuadas y proporcionadas a la evolución de la situación epidemiológica».

No cabe duda de que esta disposición parece afectar al correcto reparto de competencias entre actos legislativos y administrativos, pero hay que añadir de inmediato que en la práctica no parece haber sido objeto de aplicaciones significativas y que esta cláusula no ha sido incluida en los decretos-leyes posteriores que aclararon la distinción funcional entre fuentes primarias y secundarias.

En efecto, en las posteriores intervenciones legislativas extraordinarias, además de confirmarse sustancialmente el esquema legislativo examinado (decreto-ley y D.P.C.M.), se definen mejor los roles de las dos fuentes.

En particular, en el decreto-ley 19/2020 se prevé que «en determinadas partes del territorio nacional o, en su caso, en la totalidad del mismo, podrán adoptarse (...) una o más medidas entre las referidas en el apartado 2, por períodos predeterminados, cada uno de una duración no superior a treinta días, repetibles y modificables incluso varias veces hasta (...) el final del estado de emergencia (...) y con posibilidad de modular su aplicación aumentando o disminuyendo su intensidad según la tendencia epidemiológica». A continuación, se añade una lista de medidas definidas de forma bastante rigurosa y, sobre todo, no se volvió a incluir la cláusula general que permitía adoptar con D.P.C.M. también medidas no previstas en el elenco presente en la ley.

Con el decreto-ley 19/2020 también se definió mejor la división de poderes entre el Estado, que es el dominus del estado de excepción, y las autoridades locales, que tienen un papel subsidiario y subordinado. En particular, se prevé que «en tanto no se adopten los decretos del Presidente del Consejo de Ministros (...) y con eficacia limitada hasta ese momento, las Regiones, en relación a situaciones específicas de carácter sobrevenido de agravación del riesgo sanitario (...) podrá introducir nuevas medidas restrictivas» y que los «Alcaldes no puedan adoptar, so pena de ineficacia, ordenanzas contingentes y urgentes destinadas a hacer frente a la emergencia en contraposición a las medidas estatales» ${ }^{44}$.

43 La disposición se encuentra en el art. 3.2 del decreto-ley 6/2020.

44 La disposición se encuentra en el art. 3 del decreto-ley n. ${ }^{\circ} 19$ de 2020. 
Como se desprende de la lectura del texto, las novedades son relevantes: de hecho, los poderes extraordinarios extraestatales se reducen considerablemente para evitar el caos regulatorio que en algunas fases pareció surgir. Básicamente, las Regiones por sí solas mantienen un poder concurrente, pero el mismo tiene eficacia provisional (en cuanto entra en vigor el D.P.C.M., la ordenanza regional caduca) y debe tener un contenido más restrictivo que las disposiciones vigentes hasta entonces.

Este esquema normativo (fuente primaria implementada por fuente administrativa) se confirma en mayo de 2020 con motivo de la mejora de la situación y la consiguiente relajación de las medidas restrictivas prevista por el decreto-ley 33/2020 (convertido a través de la ley 74/2020). En dicha ocasión, la novedad es la introducción del sistema de cuatro niveles de riesgo (blanco, amarillo, naranja y rojo) mediante el cual se clasifican las Regiones según el valor de la «incidencia semanal de contagios». Esta opción legislativa racionaliza aún más la limitación de los derechos de libertad predeterminada por el acto legislativo extraordinario, mientras que la aplicación de los criterios de clasificación se otorgó a una «ordenanza del Ministro de Salud» e implicó medidas específicas adecuadas al nivel de riesgo deducido a partir de los datos epidemiológicos.

En octubre de 2020, el decreto-ley 125/2020, tras un nuevo incremento de la epidemia, se limitó a añadir más medidas restrictivas a la lista, pero no modificó la relación entre fuente primaria y fuente administrativa, ni la división de poderes extraordinarios entre el Estado y las demás entidades autónomas.

En diciembre de 2020 hubo un cambio episódico en el esquema de respuesta a la emergencia porque el decreto-ley 172/2020 estableció nuevas medidas restrictivas para el período navideño que fueron adoptadas directamente por la fuente primaria y se extendieron a todo el territorio nacional sin la intervención de actos administrativos.

Por lo demás, tras la reanudación de las actividades a principios de enero de 2021, se confirmó el sistema de niveles de riesgo y su aplicación a través de ordenanzas del Ministerio de Sanidad: este acto administrativo extraordinario se suma al D.P.C.M. que, por lo tanto, empezó a ser menos utilizado respecto de los primeros meses del estado de emergencia.

Al examinar el estado de excepción concreto — cuyo modelo se consolida sustancialmente en las posteriores intervenciones legislativas extraordinarias adoptadas en los primeros meses de 2021- es posible afirmar que la emergencia sanitaria se afrontó en cumplimiento de la Constitución y de los principios reguladores del sistema de fuentes.

El punto central está representado por el correcto uso del decreto-ley que, de conformidad con el art. 77 de la Constitución, representa el instrumento general de emergencia y tiene la función de atender eventos de emergencia («casos extraordinarios de necesidad y urgencia») que no se encuadran dentro de casos especiales como la guerra (art. 78 de la Constitución), la crisis económica (art. 81 de la Constitución), la emergencia regional (art. 126 de la Constitución). 
Al respecto, cabe destacar que no habría sido posible aplicar el estado de excepción previsto en caso de guerra ${ }^{45}$ por la simple pero insuperable consideración de que una epidemia viral es un fenómeno completamente diferente a la agresión bélica. Por lo tanto, faltó la circunstancia requerida para la activación de aquel poder.

El uso del decreto de emergencia por parte del Gobierno, además de ser legítimo por tener su fundamento en una atribución expresa de competencia del poder de emergencia (artículo 77 de la Constitución), representa una obligación constitucional específica porque, como se ha argumentado, la disposición constitucional crea una reserva de decreto-ley en casos extraordinarios de necesidad y urgencia.

Sin embargo, esta reserva no impide combinar el decreto-ley con actos extraordinarios de rango sub-primario, como los D.P.C.M., las ordenanzas del Ministro de Salud o las ordenanzas de los órganos territoriales, para ejecutar las limitaciones dispuestas unívocamente por la fuente primaria al ocurrir condiciones predeterminadas.

De manera distinta, en situaciones de emergencia anteriores (por ejemplo, en caso de desastres naturales) el Gobierno había utilizado principalmente el poder de ordenanza para derogar, aunque temporalmente, la misma legislación vigente. Tuvimos la oportunidad de criticar analíticamente la legitimidad de este modus operandi y sobre todo la capacidad de un acto formalmente administrativo de suspender y derogar normas de rango primario ${ }^{46}$. Si bien la Corte constitucional italiana haya siempre salvado la legitimidad constitucional de las normas que atribuyen el poder de ordenanza en derogación de la ley por su carácter provisional ${ }^{47}$, no hay duda de que el uso del decreto-ley como fuente primaria representa una solución preferible.

En cuanto al uso del decreto de emergencia junto con el D.P.C.M., no parece que se pueda aceptar la tesis, presentada en doctrina ${ }^{48}$, según la cual el decreto-ley debe contener necesariamente, como exige el art. 15 de la ley ordinaria del Estado 400/1988, «las medidas de aplicación inmediata, y su contenido deben ser específicos, homogéneos y correspondientes al título».

En efecto, al tratarse de una prescripción contenida en una fuente del mismo rango, el decreto-ley puede derogarla legítimamente en aplicación del criterio cronológico. Tampoco puede afirmarse que la prescripción legislativa haga explícita una disposición constitucional ya que en el texto del art. 77 de la Constitución falta cualquier referencia (literal) al contenido del decreto-ley.

45 V. CARlesimo, La gestione della pandemia da parte del Governo e il rapporto Stato-Regioni, en Diritto E Diritti, 16.10.2020, se refiere a una "posible interpretación extensiva que podría haberse utilizado ahora y en el futuro para otros casos de emergencia y no solo para el raro y obsoleto caso de guerra».

46 G. MARAzZiTa, Il conflitto tra autorità e regole: il caso del potere di ordinanza, en Rivista dell'Associazione Italiana dei Costituzionalisti, n. ${ }^{\circ} 4$ del 2010 , pp. 34 y ss.

47 G. MarazziTa, op. ult. cit., p. 31.

48 D. Trabucco, Il «virus» nel sistema delle fonti: Decreti-legge e DPCM al tempo del Covid-19 tra principio di legalità formale e principio di legalità sostanziale, en Nomos, n. ${ }^{\circ} 2$ de 2020, pp. 12 y ss. 
Asimismo, la jurisprudencia constitucional a la que nos hemos referido sobre esta temática, establece que el art. 77 «impone la conexión de todo el decreto-ley con el caso extraordinario de necesidad y urgencia, que ba inducido al Gobierno a hacer uso de la facultad excepcional de ejercer la función legislativa sin delegación previa del Parlamento» ${ }^{49}$ : por tanto, sería ilegítimo un decreto-ley que incluyera también medidas innecesarias para atender a la emergencia evocada (homogeneidad y especificidad del contenido), pero la Constitución no prohíbe al legislador extraordinario delegar la aplicación de algunas de las medidas previstas a un acto administrativo posterior.

También en el estado de excepción, como en el Derecho ordinario, es legítimo adoptar normas de distinto rango (primario y secundario) siempre que se respete el principio de legalidad en sentido sustancial: por tanto, lo importante es que el decreto-ley remita al poder administrativo extraordinario una decisión rigurosamente predeterminada respecto del an y del contenido. Esta condición parece haber sido respetada por el Gobierno italiano a excepción de la cláusula general originalmente contenida en el art. 1 del decreto-ley 6/2020 y no repetida en decretos posteriores ${ }^{50}$.

El segundo tema a considerar al evaluar la legitimidad constitucional del estado de excepción establecido para la crisis sanitaria se refiere a la limitación de derechos (por ejemplo, libertad personal, de circulación, de estudio, trabajo, reunión). También desde este punto de vista se confirma que la decisión de utilizar el poder de dictar decretos de emergencia fue correcta, porque la fuente primaria satisface plenamente el requisito de la «reserva de ley» que establece la Constitución para salvaguardar las limitaciones a los derechos y libertades fundamentales.

En cuanto a la libertad de circulación que estuvo sujeta a limitación significativa durante todo el estado de excepción, según el art. 16 de la Constitución «Todo ciudadano puede circular y residir libremente en cualquier parte del territorio nacional, excepto en caso de limitaciones que la ley establece de manera general por motivos de sanidad o seguridad». En consecuencia, el recurso al decreto-ley, en el plano formal, respeta la reserva de la ley y, en el sustancial, determinó limitaciones evidentemente caracterizadas por el requisito de la «generalidad» y fundamentadas en razones de «sanidad».

Por otro lado, respecto de las medidas que en sentido amplio afectaron a la libertad personal (la obligación de llevar mascarilla y la obligación de mantener el distanciamiento social), se trató de prescripciones con efecto obligatorio y no coercitivas que en base a la jurisprudencia constitucional recaen fuera de la reserva de jurisdicción establecida por el art. 13 de la Constitución ${ }^{51}$.

49 Corte constitucional, sentencia n. ${ }^{\circ} 22$ de 2012.

50 Como se mencionó, la cuestionable cláusula de legitimidad permitió al D.P.C.M. y en general a las «autoridades competentes» adoptar tanto las medidas definidas en el decreto-ley, como «todas las medidas de contención y gestión que sean adecuadas y proporcionadas a la evolución de la situación epidemiológica».

51 Según sentencia del Tribunal Constitucional n. ${ }^{\circ} 23$ de 1975 , la libertad personal «no incluye cualquier violación o limitación de la libertad personal, a la que el ciudadano puede ser sometido de diversas 
La última cuestión a considerar se refiere a la relación entre las fuentes estatales y las regionales en el establecimiento del estado de excepción. También desde este punto de vista, la decisión del Gobierno, avalada por el Parlamento, de centralizar la gestión de la emergencia, dejando poderes subordinados y subsidiarios a las Regiones y autoridades locales, parece cumplir con las normas constitucionales por varias razones.

En primer lugar, el art. 77, fijando una reserva de decreto-ley en casos «extraordinarios» de necesidad y urgencia, manifiesta una elección muy precisa del constituyente para arrogar al Estado los poderes extraordinarios. Si bien las Regiones tienen poderes legislativos concurrentes a los del Estado, no tienen competencias para adoptar los decretos ley bajo ninguna circunstancia. En cambio, se les reconoce un poder extraordinario de ordenanza que, sin embargo, en la relación fisiológica entre fuentes primarias y secundarias, está inevitablemente subordinado y condicionado por el poder gubernamental de emanar decretos de emergencia.

En segundo lugar, según el art. 117 de la Constitución, que establece el reparto «ordinario» de las competencias normativas entre el Estado y las Regiones, el Estado tiene la «legislación exclusiva» en materia de «seguridad del Estado», «determinación de los niveles esenciales de las prestaciones en materia de derechos civiles y sociales que deben garantizarse en todo el territorio nacional»y «profilaxis internacional». Por otro lado, la «protección de la salud» y la «protección civil» quedan incluidas en la «legislación concurrente» entre el Estado y las Regiones, pero para estas materias «la determinación de los principios fundamentales» está «reservada a la legislación del Estado».

Por lo tanto, incluso mirando el reparto ordinario de competencias, el Estado está legitimado para gobernar una crisis sanitaria cuya extensión afecta a todo el territorio nacional. El único espacio que queda para las Regiones se refiere a la posible diversificación de las medidas debido a las condiciones locales particulares, pero siempre constituye un poder subordinado y suplementario al gubernamental.

En último lugar, en cuanto al estado de excepción económico, puede constatarse que también se respetaron los requisitos constitucionales que el art. 81 plantea para el «uso de la deuda ante la ocurrencia de hechos excepcionales»: en los seis casos examinados, en efecto, el Parlamento aprobó la solicitud del Ejecutivo mediante la necesaria «autorización (...) aprobada por mayoría absoluta».

En conclusión, al examinar el modelo concreto de poderes de emergencia ejercidos durante los años 2020 y 2021 para hacer frente a la crisis sanitaria, no

formas en el desempeño de su actividad, sino únicamente actos lesivos de ese derecho que derivan su denominación tradicional del hábeas corpus, entendido como autonomía y disponibilidad de la persona misma». Por tanto, las limitaciones con efecto puramente obligatorio «no implican (...) ninguna coacción física sobre la persona, ninguna degradación jurídica, ningun menoscabo de la libertad moral que implique un sometimiento total de la persona». Para una tratación más amplia, véase G. MARAzziTA, L'inviolabilità del corpo come antagonista della grundnorm. Libertà personale e forma di Stato, en Federalismi.it, 21.4.2021. 


\section{se observan desviaciones significativas del modelo positivo de estados de excep- ción previsto por la Constitución y la legislación vigente.}

$$
* * *
$$

\section{TITLE: Italian Constitution and Covid-19 Emergency State}

ABSTRACT: This work analyses the decisions taken by Italian institutions to deal with the exceptional situation generated by the Covid-19 pandemic. In the first part, the author exposes a general theory of the exception law in the framework of the Italian constitution: an "abstract model" of the exception law and a "positive model", the one provided for in the Italian constitution. The second part analyses all the measures and provisions approved by the Italian institutions in relation to Covid-19, that form the "concrete model" of the Covid-19 right of exception. Finally, it is analysed to what extent this concrete model is in accordance with the previous models, the abstract and the positive; the conclusion is that the concrete model has been no significant deviations from those.

RESUMEN: Este trabajo analiza las decisiones adoptadas por las instituciones italianas para hacer frente a la situación excepcional generada por la pandemia de la Covid-19. Para ello, en una primera parte se elabora una teoría general sobre el derecho de excepción en el marco de la constitución italiana, que se compone de un «modelo abstracto» de derecho de excepción y un «modelo positivo», el previsto en la constitución italiana. En la segunda parte se analizan todas las medidas y disposiciones aprobadas por las instituciones italianas en relación con la Covid.19 y que forman el "modelo concreto» de derecho de excepción del Covid19. Finalmente, se analiza en qué medida este modelo concreto es conforme con los modelos anteriores, el abstracto y el positivo, y se concluye que no se han producido desviaciones significativas de estos.

KEY WORDS: Italian Constitution, exception law, emergency law, emergency state, Covid-19.

Palabras Clave: Constitución italiana, derecho de excepción, Estado de emergencia, Covid-19.

FECHA DE RECEPCIÓN: 23.05.2021

FECHA DE ACEPTACión: 20.09.2021 
